\title{
G6PD facilitates clear cell renal cell carcinoma invasion by enhancing MMP2 expression through ROS-MAPK axis pathway
}

\author{
QIAO ZHANG $^{1 *}$, QIAOQIAO HAN $^{1 *}$, ZHE YANG $^{2 *}$, YUELI NI $^{1 *}$, YANNICK LUTHER AGBANA $^{1}$, \\ HONGGANG BAI ${ }^{1,3}$, ZIHAN YI ${ }^{1,4}$, XIAOJIA YI ${ }^{1,5}$, YINGMIN KUANG ${ }^{6}$ and YUECHUN ZHU ${ }^{1}$ \\ ${ }^{1}$ Department of Biochemistry and Molecular Biology, School of Basic Medical Sciences, Kunming Medical University, \\ Yunnan, Kunming 650500; ${ }^{2}$ Department of Pathology, The First Affiliated Hospital of Kunming Medical University, \\ Yunnan, Kunming 650032; ${ }^{3}$ Department of Clinical Laboratory, The Second Hospital of Jingzhou, Jingzhou, \\ Hubei 434000; ${ }^{4}$ Department of Medical Oncology, The Third Affiliated Hospital of Kunming Medical University \\ (Tumor Hospital of Yunnan Province), Yunnan, Kunming 650118; ${ }^{5}$ Department of Pathology, The Second Affiliated \\ Hospital of Kunming Medical University, Yunnan, Kunming 650101; ${ }^{6}$ Department of Organ Transplantation, \\ The First Affiliated Hospital of Kunming Medical University, Yunnan, Kunming 650032, P.R. China
}

Received November 1, 2019; Accepted March 16, 2020

DOI: $10.3892 /$ ijo.2020.5041

\begin{abstract}
Glucose-6-phosphate dehydrogenase (G6PD) is crucial rate-limiting enzyme of the pentose phosphate pathway (PPP). G6PD dysregulation has been reported in various types of human cancer, and the role of G6PD in cancer progression was demonstrated in numerous studies. A previous study from our laboratory described the prognostic significance of G6PD in clear cell renal cell carcinoma (ccRCC), and demonstrated its proliferative role through positive feedback regulation of the phosphorylated form of signal transducer and activator of transcription 3. However, the role of G6PD in ccRCC invasion remains unclear. In the present study, reverse transcription-quantitative (RT-q) PCR, western blotting, enzyme activity assay, transwell assay and immunohistochemistry analysis in cell model, xenograft mice model and human specimen studies were performed to evaluate the role of G6PD in ccRCC invasion. The results from the present study demonstrated that G6PD may promote ccRCC cell invasive ability
\end{abstract}

Correspondence to: Professor Yuechun Zhu, Department of Biochemistry and Molecular Biology, School of Basic Medical Sciences, Kunming Medical University, 1168 Yuhua Road, Chenggong, Yunnan, Kunming 650500, P.R. China

E-mail: zhuyuechun20091119@163.com

Professor Yingmin Kuang, Department of Organ Transplantation, The First Affiliated Hospital of Kunming Medical University, 295 Xichang Road, Wuhua, Yunnan, Kunming 650032, P.R. China E-mail: yingmin1512@aliyun.com

*Contributed equally

Key words: clear cell renal cell carcinoma, glucose-6-phosphate dehydrogenase, invasion, matrix metalloproteinase 2, reactive oxygen species, MAPK by increasing matrix metalloproteinase 2 (MMP2) mRNA and protein expression both in vitro and in vivo. In addition, a positive correlation between G6PD and MMP2 expression was demonstrated by RT-qPCR and western blotting in twenty pairs of ccRCC tumor specimens and matched adjacent normal tissues. Furthermore, G6PD promoted reactive oxygen species (ROS) generation and activated the MAPK signaling pathway in ccRCC cells. In addition, ROS significantly promoted the MAPK signaling pathway activation, which in turn contributed to MMP2 overexpression in ccRCC cells. In conclusion, the present study demonstrated that G6PD may facilitate ccRCC cell invasive ability by enhancing MMP2 expression through ROS-MAPK axis pathway.

\section{Introduction}

Kidney cancer global incidence and mortality rate have been increasing worldwide. In 2016, there were 342,000 cases of kidney cancer, and $\sim 400,000$ new cases were recorded in 2017 (1,2). According to the last estimations from the United States, 73,750 new cases of kidney malignancy and 14,830 mortality cases were expected to occur in 2020 (3). Renal cell carcinoma (RCC) is the most common form of kidney cancer, and clear cell RCC (ccRCC) represents the main histological subtype of RCC, accounting for $80-90 \%$ of all cases $(4,5)$. At the time of diagnosis, $25-30 \%$ of patients with ccRCC present with metastasis $(4,6)$. It is therefore crucial to determine the underlying mechanisms of ccRCC progression in order to develop novel strategies for ccRCC treatment.

Metabolic disorders, including the 'Warburg effect' and rapid production of ATP and building blocks for the synthesis of nucleotides, lipids and amino acids, are recognized as hallmark of cancer $(7,8)$ and have thus attracted growing interest. Previous studies have investigated the diagnostic, prognostic and therapeutic role of enhanced glucose catabolism, especially the aerobic glycolysis, in cancer (9-11). In particular, the pentose phosphate pathway (PPP) is a major pathway of 
glucose metabolism that has been widely implicated in cancer growth and metastasis. This pathway generates nucleotides biosynthesis precursors and NADPH for anabolic reactions and redox balance maintenance, which are necessary for cancer cell proliferation. This reaction is only possible in presence of glucose-6-phosphate dehydrogenase (G6PD) (12). G6PD, which is the principal rate-limiting enzyme of the PPP, is the main actor in PPP-mediated cancer progression $(8,12)$. Furthermore, G6PD can cooperate with numerous signaling pathways in order to promote cancer, and G6PD was reported to be overexpressed in various types of tumor, including breast carcinoma, ccRCC and lung adenocarcinoma (13-15). Previous work from our laboratory described the prognostic significance of G6PD in ccRCC, and demonstrated its role in promoting tumor growth through positive feedback regulation of phospho-signal transducer and activator of transcription 3 (p-STAT3) $(14,16)$. However, G6PD ability to promote ccRCC invasion remains unknown.

It has been reported that G6PD serves key roles in reactive oxygen species (ROS) accumulation. Previous results from our laboratory demonstrated that G6PD could promote ROS generation by increasing NADPH oxidase 4 activity in ccRCC (16). Furthermore, increased oxidative stress is an important factor leading to abnormal intracellular signal transduction $(17,18)$. ROS can induce continuous activation of pSTAT3, NF- $\mathrm{B}$ and mitogen-activated protein kinase (MAPK) signaling pathways $(16,19-24)$ and promote the growth of certain cancer, including ccRCC, melanoma and liver cancer, regulate angiogenesis, and accelerate tumor metastasis by promoting the expression of a series of proliferation- and metastasis-related genes, including cyclinD1 and matrix metalloproteinases (MMPs) (16,25-27).

Tumor metastasis is a multistep process that involves cell invasion, intravasation, arrest, extravasation and metastatic colonization (28). During the initiation phase of the metastatic process (invasion), the extracellular matrix (ECM) deteriorates to facilitate tumor cell adherence $(28,29)$. In addition, MMPs are strongly implicated in the degradation of the $\operatorname{ECM}(30,31)$, which emphasizes their crucial role in cancer metastasis. In particular, MMP2 has been reported to be upregulated in RCC and to participate in the invasiveness of RCC cells (32-34). MAPK signaling pathway participates in MMP2 activation and ccRCC cell metastasis (35). These evidences indicate that there may be a correlation between ROS, MAKP signaling pathway and MMP2 expression, and may be involved in ccRCC invasion. However, the underlying mechanism between these factors and how they exert the role in ccRCC invasion are not clear.

The present study evaluated the role of G6PD in ccRCC invasion. To do so, the underlying mechanisms of G6PD in ccRCC invasion, and the association between G6PD expression, MMPs expression and ROS-MAPK signaling pathway were investigated.

\section{Materials and methods}

Stable cell line establishment and cell treatment. The ccRCC cells Caki-1 (ATCC HTB-46 ${ }^{\mathrm{TM}}$ ), ACHN (ATCC CRL-1611 ${ }^{\mathrm{TM}}$ ) and 786-O (ATCC CRL-1932 $2^{\mathrm{TM}}$ ) were purchased from Kunming Institute of Zoology (Chinese
Academy of Sciences) and were cultured in McCOY's 5A media (cat. no. M9309; Sigma-Aldrich; Merck KGaA), MEM (cat. no. 10370-021; Gibco; Thermo Fisher Scientific, Inc.) and RPMI-1640 (cat. no. 11875-085; Gibco; Thermo Fisher Scientific, Inc.), respectively, supplemented with $10 \%$ fetal bovine serum (FBS; cat. no. 16140071; Thermo Fisher Scientific, Inc.). Cells were placed at $37^{\circ} \mathrm{C}$ in a humidified incubator containing $5 \% \mathrm{CO}_{2}$.

Cells were transfected in order to knockdown or overexpress G6PD as previously described (16). To construct G6PD-knocked down Caki-1 stable cells, $2 \times 10^{5}$ Caki- 1 cells were seeded in a 6-well plate. When they reached $70-80 \%$ confluence, cells were transfected with $2 \mu \mathrm{g}$ of pSR-GFP/Neo-G6PD shRNA (G6PD-KD; sequence, 5'-GATCCCCGCCTCAGTGCCACT TGACATTCAAGAGATGTCAAGTGGCACTGAGGCTTT TTTA-3') or pSR-GFP/Neo-Non-silencer control plasmid (Non-silencer; sequence, 5'-GATCCCCTTCTCCGAACGTGT CACGTTTCAAGAGAACGTGACACGTTCGGAGAATTT TTTA-3') by using Lipofectamine 2000 (cat. no. 11668019; Invitrogen; Thermo Fisher Scientific, Inc.). After $48 \mathrm{~h}$ transfection, cells were treated with G418 (cat. no. E859-1g; Amresco, LLC) at the concentration of $1,000 \mu \mathrm{g} / \mathrm{ml}$ for 3 weeks for resistance selection. For the establishment of the G6PD-overexpressing ACHN cells, $2 \times 10^{5}$ ACHN cells were seeded in a 6-well plate. When they reached $70-80 \%$ confluence, cells were transfected with $2 \mu \mathrm{g}$ pBABE-puro-G6PD (G6PD-OE) or pBABE-puro (Control) plasmid using Lipofectamine 2000. After $48 \mathrm{~h}$ transfection, puromycin (cat. no. J598-25 mg; Amresco, LLC) was used at $0.5 \mu \mathrm{g} / \mathrm{ml}$ for 3 weeks for resistance selection.

The ROS scavenger N-acetylcysteine (NAC; cat. no. A7250; Sigma-Aldrich; Merck KGaA) was dissolved in DMSO to prepare a $600 \mathrm{mM}$ stock solution. The ROS stimulator $\mathrm{H}_{2} \mathrm{O}_{2}$ (cat. no. sc-203336) was purchased from Santa Cruz Biotechnology, Inc. 786-O cells were treated with NAC (20 mM) for $24 \mathrm{~h}$ or $\mathrm{H}_{2} \mathrm{O}_{2}(1 \mathrm{mM})$ for $2 \mathrm{~h}$ (16). The MAPK signaling pathway inhibitors SP600125 (cat. no. M2076), SB203580 (cat. no. M1781) and U0126 (cat. no. M1977) were purchased from Abmole Bioscience Inc. and dissolved in DMSO to prepare 200, 113.9 and $200 \mathrm{mM}$ stock solutions, respectively. Cells were treated with SP600125, SB203580 and $\mathrm{U} 0126$ at 5,10 or $20 \mu \mathrm{M}$, respectively, for $24 \mathrm{~h}$ (36-40). All stock solutions were stored at $-20^{\circ} \mathrm{C}$. For cell treatment, each stock solution was diluted with the culture medium and added to the medium according to the final concentrations.

Animal model establishment. All animal experiments were performed according to the Regulations for the Administration of Affairs Concerning Experimental Animals (China, 1988) and approved by the Institutional Animal Care and Use Committee of Kunming Medical University. Six-week-old specific pathogen-free nude mice $(n=20)$ were purchased from Beijing HFK Bioscience Co., Ltd and kept in the department of Animal Technology and Science of Kunming Medical University at $25 \pm 2^{\circ} \mathrm{C}, 40-60 \%$ humidity, $12 / 12 \mathrm{~h}$ dark/light cycle and 10-15 times/h ventilation. Animals had free access to food and water. Mice were subcutaneously injected with 1x10 ${ }^{6}$ G6PD knocked down Caki-1 cells, G6PD overexpressing ACHN cells or relevant control cells into the mice oxter flank (5 mice per group). Tumor size was measured every five days 
(on days 7, 12, 17, 22, 27, 32, 37, 42 and 47 post-injection) by using the following formula: Tumor size=length $\mathrm{x}$ width ${ }^{2} / 2$ as described previously (40). Mice were euthanized by intraperitoneal injection of $200 \mathrm{mg} / \mathrm{kg}$ pentobarbital sodium (cat. no. P3761; Sigma-Aldrich; Merck KGaA) after the last measurement and tumors were harvested for further analysis.

Reverse transcription-quantitative $(R T-q) P C R$. Total RNA was extracted from all cells, human ccRCC specimens and adjacent normal tissues and xenograft mice model tissues by using Trizol reagent (cat. no. 15596-018; Invitrogen; Thermo Fisher Scientific, Inc.) according to the manufacturers' protocol. Synthesis of cDNA was conducted on $2 \mu \mathrm{g}$ of total RNA per sample by using RevertAid First Strand cDNA Synthesis Kit (cat. no. K1622; Thermo Fisher Scientific, Inc.) according to the manufacturers' protocol. RT-qPCR was performed as described previously by using FastStart Universal SYBR Green Master (cat. no. 04913914001; Roche Diagnostics) $(40,41)$ for the evaluation of U6, G6PD and MMPs, including MMP1, MMP2, MMP7, MMP9, MMP10 and MMP13 expression levels using ABI Prism 7700 Real-Time PCR System (Thermo Fisher Scientific, Inc.). The $20-\mu 1$ reaction mixture contained $10 \mu \mathrm{l}$ of $2 \times$ Mix SYBR Green buffer, $1 \mu 1$ of forward primer $(0.3 \mu \mathrm{M}), 1 \mu \mathrm{l}$ of reverse primer $(0.3 \mu \mathrm{M}), 1 \mu \mathrm{l}$ of PCR template (20 ng) and $7 \mu \mathrm{l}$ of RNA-free water. PCR running steps were as follows: Pre-denaturation at $95^{\circ} \mathrm{C}$ for $10 \mathrm{~min}, 40$ cycles of $95^{\circ} \mathrm{C}$ for $15 \mathrm{sec}$ and $60^{\circ} \mathrm{C}$ for $1 \mathrm{~min}$. The relative expressions levels were normalized to the endogenous control U6 and were expressed as $2^{-\Delta \Delta \mathrm{Cq}}(42)$. The sequences of the primers are presented in Table I.

Western blotting. Western blotting was performed as previously described $(16,40)$. All cells, human ccRCC specimens and adjacent normal tissues and xenograft mice model tissues were lysed using RIPA lysis buffer (cat. no. R0010; Beijing Solarbio Science \& Technology Co., Ltd.) containing protease inhibitors (cat. no. B14001; Biotoolmake) for $30 \mathrm{~min}$ at $4^{\circ} \mathrm{C}$. Lysates were centrifuged at $14,010 \mathrm{x}$ g for $10 \mathrm{~min}$ at $4^{\circ} \mathrm{C}$. Protein concentration was determined by using BCA protein assay kit (cat. no. 23225; Thermo Fisher Scientific, Inc.). Proteins $(50 \mu \mathrm{g})$ were separated by $10 \%$ SDS-PAGE and transferred onto polyvinylidene difluoride membrane. Non-specific binding sites were blocked by using Tris-buffer (50 mM Tris, $\mathrm{pH} 7.5$ ) containing 5\% fat-free milk and $0.1 \%$ Tween-20 at room temperature for $1 \mathrm{~h}$. Membranes were then incubated with primary antibodies overnight at $4^{\circ} \mathrm{C}$. Details of the antibodies used in the present study are presented in Table II. Subsequently, corresponding HRP-conjugated secondary antibodies were added and incubated at room temperature for $1 \mathrm{~h}$. After extensive washing, bands were detected by Bio-Rad ChemiDoc XRS+ chemiluminescence imaging system using an enhanced chemiluminescence advanced detection kit (cat. no. 34077; Thermo Fisher Scientific, Inc.). Relative expression levels were normalized to endogenous control using Image J software (version 1.46; National Institutes of Health).

G6PD and MMP2 activity assay. G6PD activity was evaluated in G6PD-knocked down Caki-1 cells, G6PD-overexpressing ACHN cells and their controls by using the G6PD assay kit (cat. no. GMS70013.1; Genmed) according to the manufacturers' protocol and as previously described (16). The activity of G6PD was analyzed by detecting the change of NADPH in the reaction system. Total protein was extracted according to the instructions of the kit and the total protein concentration was determined by using BCA protein assay kit. The active unit of G6PD was defined as follows: 1 unit of enzyme catalyzed the conversion of 1 mole of glucose 6-phosphate to 6-glucosonolactone and the formation of 1 mole of NADPH at $1 \mathrm{~min}$ at $37^{\circ} \mathrm{C}$. Absorbances were detected at OD $340 \mathrm{~nm}$ by U-1800 ultraviolet spectrophotometer (Hitachi, Japan). The specific activity of G6PD was calculated according to the total protein concentration and enzyme activity.

MMP2 activity was evaluated in stable transfected cells and correponding controls by using the MMP2 activity assay kit (cat. no. GMS50070.1; Genmed) according to the manufacturers' instructions. MMP2 activities were measured by using fluorescence resonance energy transfer method (FRET) $(43,44)$. In the present study, the donor fluorescent probe was 7-methoxycoumarin which was labeled with the peptide substrate PLGLAR. The polypeptide Gly-Leu bond would be hydrolyzed by MMP2, followed by the 7-methoxycoumarin polypeptide fragment release and subsequent fluorescence exhibition. The 7-methoxycoumarin concentration and MMP2 activities were estimated using standard curve which was plotted by fluorescence intensity (exciting light, $330 \mathrm{~nm}$; emitting light, $400 \mathrm{~nm}$ ).

Cell invasion assay. Transwell chambers $(8 \mu \mathrm{M}$, Costar; Corning, Inc.) in 24-well plates were used for the cell invasion assay. Cell medium containing 10\% FBS $(800 \mu \mathrm{l})$ was added in the lower chamber, and $5 \times 10^{4}$ of G6PD-knocked down Caki-1 cells, G6PD-overexpressing ACHN cells or their control cells in $200 \mu \mathrm{l}$ serum-free medium were seeded into the upper chamber of the Transwell previously precoated with Matrigel for $48 \mathrm{~h}$. Subsequently, Transwell membranes were fixed with $4 \%$ formaldehyde for $15 \mathrm{~min}$ at room temperature and stained with crystal violet for $10 \mathrm{~min}$. A total of $10 \mathrm{micro}-$ scopic fields captured by Leica DM 300 (Leica Microsystems $\mathrm{GmbH}$; magnification, x100) were randomly chosen and cell numbers were counted to determine the cell invasive ability. Experiments were repeated three times, and each sample was assessed in triplicate.

Immunohistochemistry (IHC). Xenografted mice tumor tissues were fixed in $4 \%$ paraformaldehyde for $12 \mathrm{~h}$ at room temperature, and dehydrated by using ascending alcohol series ( $70 \%$ for 2 h, $80 \%$ for $1 \mathrm{~h}, 85 \%$ for $1 \mathrm{~h}, 90 \%$ for $1 \mathrm{~h}, 95 \%$ for $1 \mathrm{~h}$, anhydrous ethano 1 for $1 \mathrm{~h}$, anhydrous ethanol 2 for $1 \mathrm{~h}$, xylene 1 for $30 \mathrm{~min}$, xylene 2 for $35 \mathrm{~min}$ ). Paraffin-embedded blocks were cut into $3-\mu \mathrm{m}$ thick sections and used for IHC analysis for G6PD or MMP2 expression by using antibodies presented in Table II.

The experiments involving human samples were performed in accordance with the regulations of Helsinki Declaration and approved by the Ethics Committee of Kunming Medical University and patients provided signed informed consent. In the present study, 20 patients diagnosed with primary ccRCC between February 2014 and September 2017 (age range, 43-78 years; average age, 56 year) were included. Fresh ccRCC specimens and adjacent normal renal tissues from 
Table I. Sequences of the primers used for reverse transcription quantitative PCR.

\begin{tabular}{llc}
\hline Primers & \multicolumn{1}{c}{ Primer sequences (5'-3') } & Product size, bp \\
\hline U6 & & 94 \\
Forward & CTCGCTTCGGCAGCACA & 167 \\
Reverse & AACGCTTCACGAATTTGCGT & \\
G6PD & & 82 \\
Forward & TCATCATCATGGGTGCATCGG \\
Reverse & CTTGAAGAAGGGCTCACTCTGTTTG & 178 \\
MMP1 & & \\
Forward & AAAATTACACGCCAGATTTGCC & 158 \\
Reverse & GGTGTGACATTACTCCAGAGTTG & \\
MMP2 & & \\
Forward & CAGGGAATGAGTACTGGGTCTATT & 207 \\
Reverse & ACTCCAGTTAAAGGCAGCATCTAC & \\
MMP7 & & \\
Forward & GAGTGAGCTACAGTGGGAACA & 103 \\
Reverse & CTATGACGCGGGAGTTTAACAT & \\
MMP9 & & 103 \\
Forward & AATCTCTTCTAGAGACTGGGAAGGAG & \\
Reverse & AGCTGATTGACTAAAGTAGCTGGA & \\
MMP10 & TGCTCTGCCTATCCTCTGAGT & \\
Forward & TCACATCCTTTCGAGGTTGTAG & \\
Reverse & ACTGAGAGGCTCCGAGAAATG & \\
MMP13 & GAACCCCGCATCTTGGCTT & \\
Reverse & &
\end{tabular}

Table II. Antibodies used for western blotting and immunohistochemistry.

\begin{tabular}{|c|c|c|c|}
\hline Name & Supplier & Cat. no. & Dilution \\
\hline Anti-G6PD & Abcam & ab133525 & $1: 2,000$ for $\mathrm{WB} ; 1: 200$ for $\mathrm{IHC}$ \\
\hline Anti-MMP2 & Abcam & ab110186 & $1: 2,000$ for $\mathrm{WB} ; 1: 1,000$ for $\mathrm{IHC}$ \\
\hline Anti- JNK1+JNK2+JNK3 & Abcam & ab208035 & $1: 2,000$ for $\mathrm{WB}$ \\
\hline $\begin{array}{l}\text { Anti-JNK1+JNK2+JNK3 } \\
\text { (phospho T183+T183+T221) }\end{array}$ & Abcam & ab124956 & $1: 1,000$ for WB; $1: 100$ for IHC \\
\hline Anti-p38 & Abcam & ab170099 & $1: 2,000$ for $W B$ \\
\hline Anti-p38 (phospho T180) & Abcam & ab178867 & $1: 1,000$ for $\mathrm{WB} ; 1: 500$ for IHC \\
\hline Anti-ERK1/2 (C-9) & Santa Cruz Biotechnology, Inc. & sc-514302 & $1: 1,000$ for $\mathrm{WB}$ \\
\hline $\begin{array}{l}\text { Anti-ERK1 (phospho Y204) + ERK2 } \\
\text { (phospho Y187) }\end{array}$ & Abcam & ab47339 & $1: 1,000$ for $\mathrm{WB} ; 1: 200$ for IHC \\
\hline Anti-GAPDH & ProteinTech Group, Inc. & 10494-1-AP & $1: 5,000$ for $\mathrm{WB}$ \\
\hline Anti- $\beta$-actin & Cell Signaling Technology & 4967 & $1: 1,000$ for $W B$ \\
\hline $\begin{array}{l}\text { HRP-conjugated goat anti-rabbit IgG } \\
\text { secondary antibody }\end{array}$ & Santa Cruz Biotechnology, Inc. & sc-2004 & $1: 1,000$ for $\mathrm{WB}$ \\
\hline $\begin{array}{l}\text { HRP-conjugated goat anti-mouse } \operatorname{IgG} \\
\text { secondary antibody }\end{array}$ & Santa Cruz Biotechnology, Inc. & sc-2005 & $1: 1,000$ for $\mathrm{WB}$ \\
\hline
\end{tabular}

these included patients were obtained from the Department of Organ Transplantation of the First Affiliated Hospital of
Kunming Medical University and immediately frozen and stored in liquid nitrogen. Corresponding paraffin-embedded 
sections (3- $\mu \mathrm{m}$ thick) including tumor and adjacent normal tissues from the same patients with ccRCC were obtained from the Department of Pathology of the First and Second Affiliated Hospital of Kunming Medical University.

IHC was performed as previously described $(14,40)$ by using antibodies presented in Table II. Firstly, paraffin sections of xenografted mice tumor, human ccRCC or adjacent normal tissues were dewaxed in xylene at room temperature and rehydrated by using decreasing ethanol series $(100 \%$ twice, and 90, 80, 70 and $60 \%$ once, 5 min each time at room temperature). Antigen retrieval was performed using $0.01 \mathrm{M}$ citric acid buffer (pH 6.0; cat. no. C1010; Beijing Solarbio Sciences \& Technology Co., Ltd.) at high pressure for 2 min. IHC was conducted by using General-purpose two-step detection kit (cat. no. PV-9000; ZSGB-BIO.) according to the manufacturers' instructions. Endogenous peroxidase activity was blocked using $3 \% \mathrm{H}_{2} \mathrm{O}_{2}$ for $10 \mathrm{~min}$ at room temperature. Sections were incubated with primary antibodies overnight at $4^{\circ} \mathrm{C}$. A volume of $200 \mu \mathrm{l}$ reaction enhancement solution was added onto the sections for $20 \mathrm{~min}$ at room temperature, followed by $200 \mu 1$ enhanced enzyme-labeled sheep anti-mouse/rabbit polymer after three washes with PBS for $20 \mathrm{~min}$ at room temperature. Tissues were stained by using DAB detection kit (cat. no. DAB-2031; MXB Biotechnologies) for 5-8 min at room temperature, incubated with hematoxylin (cat.no.ZLI-9615; ZSGB-BIO.) for $20 \mathrm{sec}$ at room temperature, dehydrated by using ascending ethanol series $(60,70,80$ and $90 \%$ once, $100 \%$ twice, 5 min each time at room temperature) and mounted onto glass slides by using neutral resin adhesive (cat. no. G8590; Beijing Solarbio Science \& Technology Co., Ltd.). Sections were imaged using a Leica DM25000B microscope (Leica Microsystems, Inc.).

For IHC analysis, 10 areas per section were examined and captured using a Leica DM25000B microscope (magnification, $\mathrm{x} 400$ ). The expression score of detected factors in ccRCC was determined as follows: Staining intensity $\mathrm{x}$ percentage of stained cells, which ranged from 0-12 points. Staining intensity was classified as follows: Negative (0 point), weak (1 point), moderate ( 2 points) and strong ( 3 points). Percentage of positive stained cells was as follows: $<25 \%$ ( 1 point), $26-50 \%$ ( 2 points), $51-75 \%$ ( 3 points) or $>75 \%$ ( 4 points). Two blinded independent investigators analyzed the sections. Patients with final staining scores $>4$ points were considered to have high protein expression.

ROS level detection. ROS accumulation level in ccRCC cells was determined with the fluorescent probe dihydroethidium (DHE; cat. no. R001; Vigorous Biotechnology) by using flow cytometry as previously described (27). 786-O cells were seeded in a 6 -well plate at the density of $5 \times 10^{5}$ cells/well and cultured for $12 \mathrm{~h}$. After stimulated with NAC (20 mM) for $24 \mathrm{~h}$ or $\mathrm{H}_{2} \mathrm{O}_{2}(1 \mathrm{mM})$ for $2 \mathrm{~h}, 786-\mathrm{O}$ cells were washed twice with PBS. DHE solution dissolved in medium was added to each well at the final concentration of $50 \mu \mathrm{M}(2 \mathrm{ml})$. Blank control cells were incubated with $2 \mathrm{ml}$ fresh medium. Incubation with the probe lasted for $1 \mathrm{~h}$ at $37^{\circ} \mathrm{C}$ in the dark. Cells were washed twice with PBS. Single cell suspension was prepared following trypsin digestion and resuspended into $0.5-1 \mathrm{ml}$ cold PBS. Fluorescence intensity was determined using PARTEC CyFlow Space flow cytometer equipped with FlowJo software (version 10.6.1) (excitation light, $530 \mathrm{~nm}$; emission light, $620 \mathrm{~nm})$.

Statistical analysis. SPSS (version 21.0; IBM Corp.) was used for data analysis. $\chi^{2}$ test was used for IHC analysis. Pearson correlation analysis was used to analyze the correlation between expression level of two different genes. Unpaired or paired Student's t-test was used for comparison between two groups, and differences between multiple groups were compared with on-way ANOVA followed by Bonferroni post hoc test. Comparisons in mouse xenograft models were determined using mixed ANOVA and bonfferoni test was used for confidence interval adjustment. Data were presented as the means \pm standard deviation. $\mathrm{P}<0.05$ was considered to indicate a statistically significant difference. Graphs were designed using GraphPad Prism (version 6.0; GraphPad Software, Inc.).

\section{Results}

G6PD stimulates ccRCC cell invasive ability. The expression level and activity of G6PD in the non-transfected and transfected cell lines were evaluated. As G6PD is naturally more expressed in Caki-1 cells compared with ACHN cells (16), G6PD was knocked down and overexpressed in Caki-1 and ACHN cells, respectively. The results demonstrated that G6PD mRNA and protein expressions were decreased in the Caki-1-G6PD knocked down cells, as well as the G6PD activity compared with Caki-1-non-silencer cells. In addition, mRNA expression, protein expression and G6PD enzyme activity in G6PD overexpressing ACHN cells were increased compared with non-transfected cells (Fig. 1A-C). These results demonstrated the stable successful transfections of these cell lines.

Subsequently, the role of G6PD on ccRCC invasive ability was examined. The results demonstrated that the invasion ability of Caki-1-G6PD knocked down cells was significantly decreased compared with non-transfected cells, whereas the invasion ability of G6PD-overexpressing ACHN cells was significantly increased compared with ACHN non-transfected cells (Fig. 1D and E). These results indicated that G6PD may facilitate ccRCC invasive ability.

G6PD promotes and is positively correlated with MMP 2 expression in ccRCC cells. In order to explore how G6PD may contribute to ccRCC invasion, the influence of G6PD on MMPs, which are key enzymes implicated in cancer invasion, was investigated. The results demonstrated that none of the mRNA expression changes of MMPs family members, including MMP1, MMP7, MMP9, MMP10, MMP13 were consistent with that of G6PD in stably transfected ccRCC cell lines (Fig. S1). Specifically, MMP2 and MMP7 mRNA expression was increased in G6PD-knocked down Caki-1 cells compared with Caki-1-non-silencer cells, but decreased in G6PD-overexpressing ACHN cells (Fig. S1A-B). In addition, the expression of MMP9 was not modified following G6PD knockdown or overexpression (Fig. S1C). In addition, MMP10 mRNA expression was significantly increased in G6PD-overexpressing ACHN cells, which was not the case for MMP13 mRNA expression. MMP10 and MMP13 mRNA expression was increased in G6PD-knocked down Caki-1 cells 

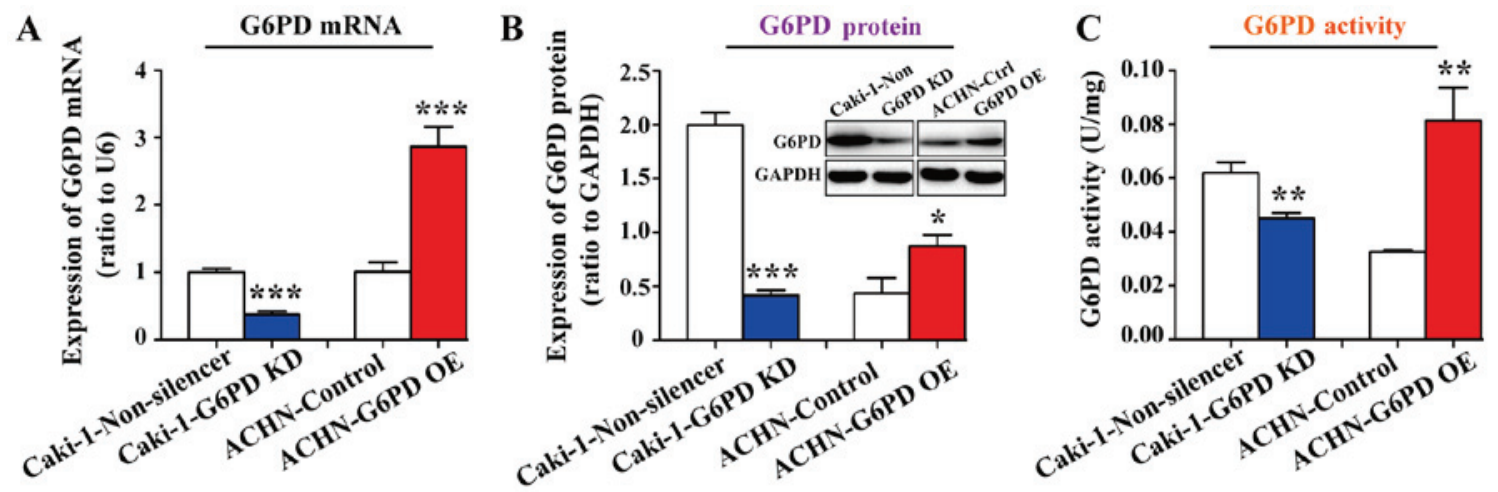

D

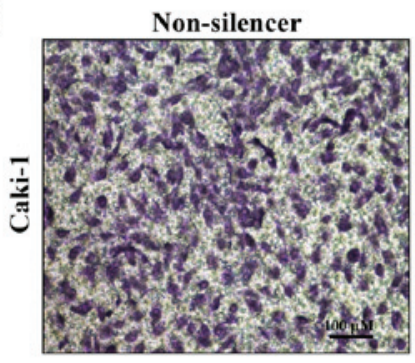

Control

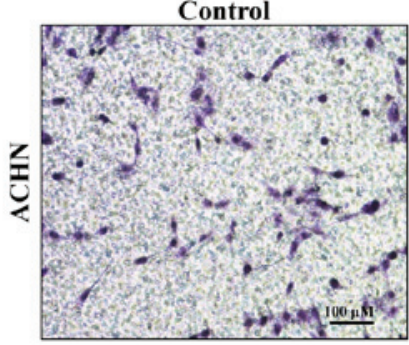

G6PD KD

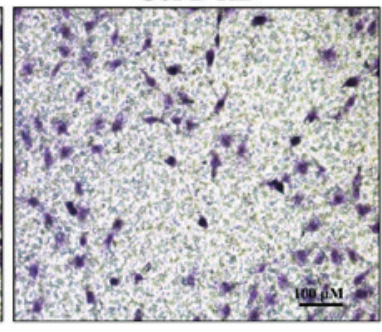

G6PD OF

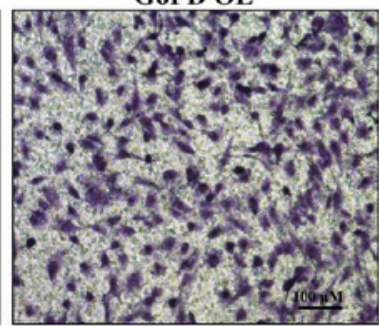

E

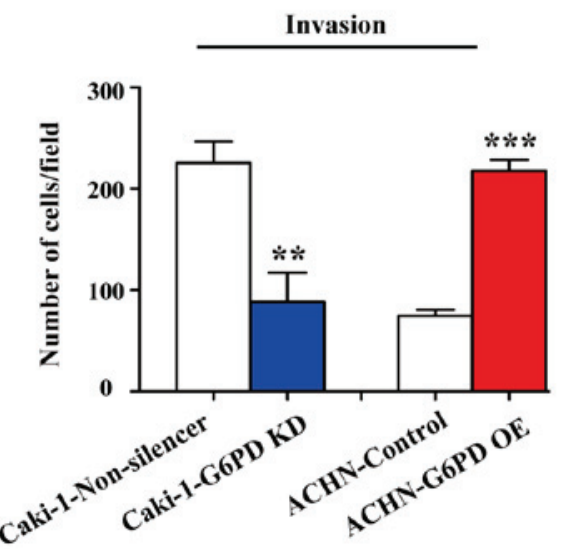

Figure 1. G6PD facilitated ccRCC cell invasion. G6PD expression in ccRCC stably transfected cells were detected by (A) reverse transcription quantitative PCR and (B) western blotting. (C) G6PD activity in ccRCC stable transfected cells. (D) Representative images of the invasive ability of G6PD knocked down or overexpressing ccRCC cells (Scale bar $=100 \mu \mathrm{m}$ ). (E) Quantification of the cell invasive ability. $\mathrm{n}=3$. Data were expressed as the means \pm standard deviation. ${ }^{*} \mathrm{P}<0.05,{ }^{* *} \mathrm{P}<0.01$ and ${ }^{* * *} \mathrm{P}<0.001$ vs. non-silencer or control cells. ccRCC, clear cell renal cell carcinoma; G6PD, glucose-6-phosphate dehydrogenase; $\mathrm{KD}$, knockdown; OE, overexpressing.

(Fig. S1D-E). In G6PD-knocked down Caki-1 cells, MMP2 mRNA expression was decreased, but increased by 2 -fold in G6PD-overexpressing ACHN cells (Fig. 2A).

The protein expression and activity of MMP2 in different stable cell lines was therefore evaluated. As presented in Fig. 2B and C, MMP2 was highly expressed in G6PD overexpressing ACHN cell lines, whereas it was decreased in G6PD-knocked down Caki-1 cell lines (Fig. 2B). In G6PD-knocked down Caki-1 cells, MMP2 activity was decreased; however, in G6PD overexpressing cells, MMP2 activity was increased by 0.8 -fold (Fig. 2C). MMP2 and G6PD expression was also analyzed in 20 pairs of ccRCC tumor and matched adjacent normal tissues. The results demonstrated that MMP2 and G6PD mRNA and protein expressions were increased in tumor tissues compared with normal tissues (Fig. 2D and F-H). Furthermore, results from IHC demonstrated that MMP2 was significantly overexpressed in tumor tissues compared with normal tissues (Fig. 2J and K). In addition, the results from Pearson correlation analysis demonstrated that G6PD and MMP2 were positively correlated at the mRNA (Fig. 2E) and protein (Fig. 2I) levels ( $\mathrm{r}=0.6003$, $\mathrm{P}<0.01$; and $\mathrm{r}=0.5142, \mathrm{P}<0.05$; respectively). These findings indicated that G6PD may promote ccRCC cell invasion, which may be due to enhanced MMP2 expression in ccRCC cells. However, how G6PD, which is an enzyme mainly localized into the cytoplasm, could positively regulate MMP2 remains unclear and requires further investigation.

G6PD overexpression stimulates ROS accumulation and activates MAPK signaling pathway in ccRCC cells. It has been established that G6PD stimulates ROS production in ccRCC cell lines (16). As presented in Fig. 3A-C, results were consistent with our previous study using other ccRCC cell lines (16). The results demonstrated that ROS accumulation was significantly decreased in G6PD-knocked down Caki-1 cells compared with the Non-silencer cells (Fig. 3A-C, left panel); however, G6PD overexpression increased ROS levels in ACHN cells compared with control cells (Fig. 3A-C, right panel). It has been reported that MAPK signaling pathway serves a key role in MMP2 activation and ccRCC cell metastasis stimulation $(19,35)$. However, the underlying mechanisms remain unknown. Subsequently, the present study hypothesized that G6PD may activate MAPK signaling pathway following increased ROS accumulation in the cytoplasm, leading to increased MMP2 expression in ccRCC cells. Western blotting was therefore used to determine 
A
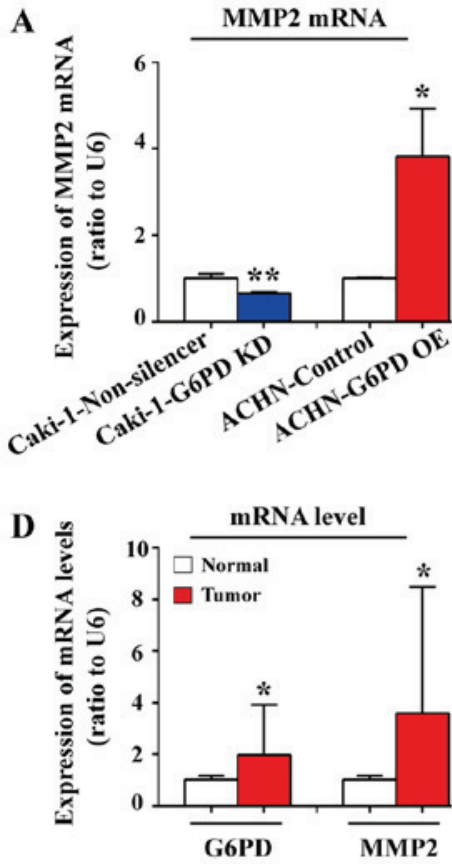

G

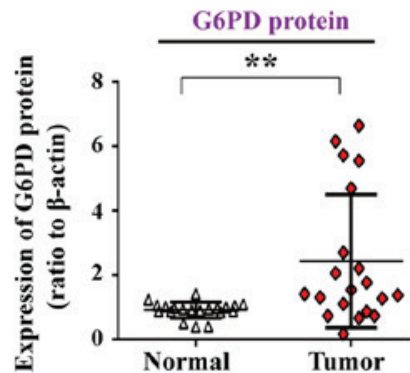

$\mathbf{J}$

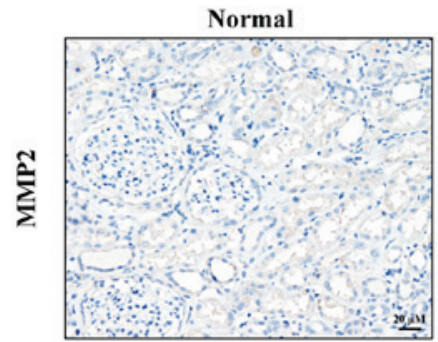

B

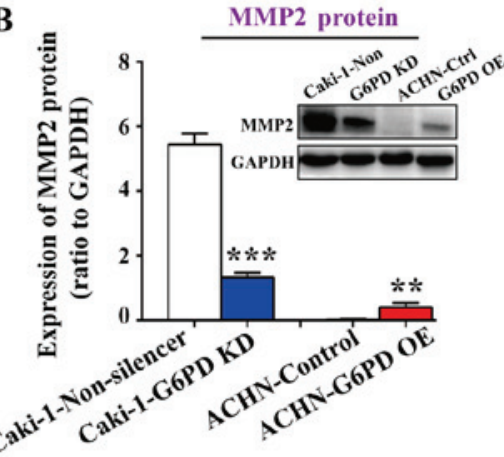

E

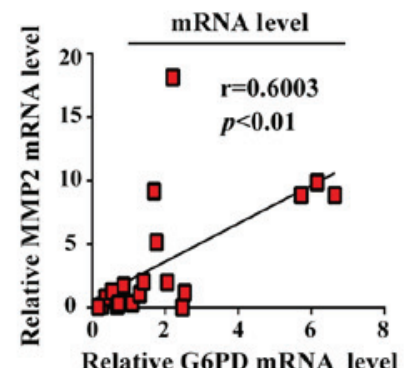

$\mathbf{H}$
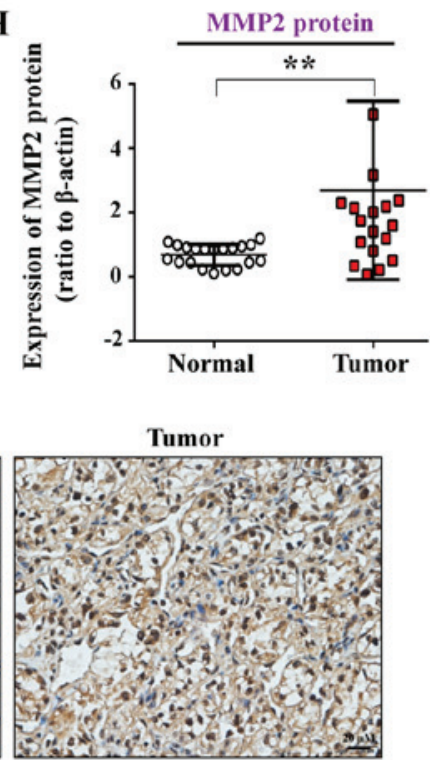

C
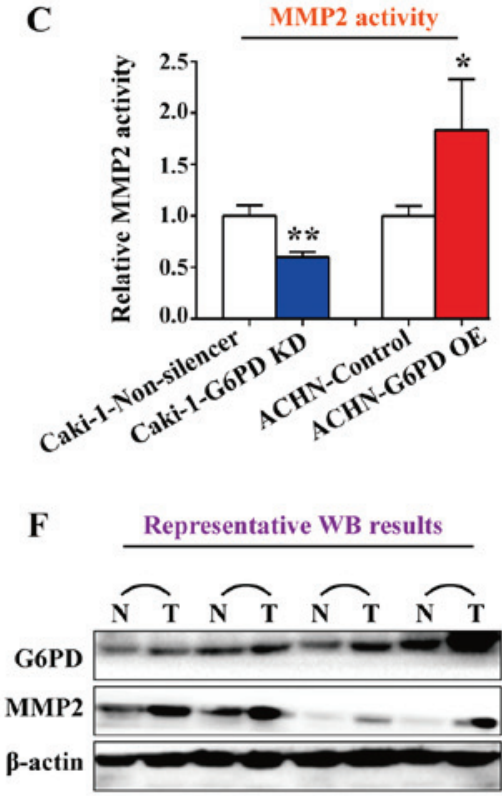

I

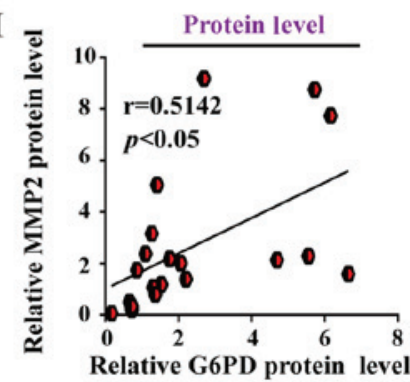

K

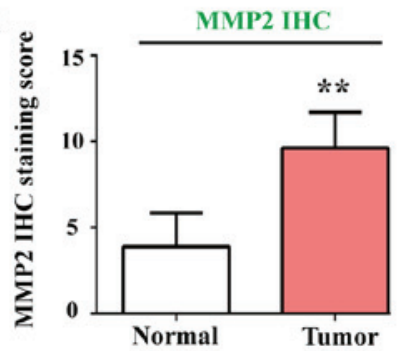

Figure 2. G6PD promoted and was positively correlated with MMP2 expression in ccRCC cells. MMP2 mRNA and protein expression in stable transfected Caki-1 or ACHN cells were analyzed by (A) RT-qPCR and (B) western blotting, respectively. (C) MMP2 activities in stable transfected Caki-1 or ACHN cells was detected by assay kit, and raw data (fluoresence intensity) were transferred into the relative activity changes compared with each control. Evaluation of G6PD and MMP2 expression was conducted in 20 pairs of ccRCC tumor specimens and matched adjacent normal tissues by using (D) RT-qPCR and (F-H) western blotting. Pearson correlation analysis between (E) MMP2 and G6PD mRNA expression and (I) MMP2 and G6PD protein expression. Each analysis was performed at least three times and each sample assessed in triplicate. Data were expressed as the means \pm standard deviation. ${ }^{*} \mathrm{P}<0.05,{ }^{* * *} \mathrm{P}<0.01$ and ${ }^{* * *} \mathrm{P}<0.001$ vs. non-silencer, control or adjacent normal tissues. (J) IHC analysis of MMP2 expression in 20 pairs of ccRCC specimens and matched adjacent normal tissues. Scale bar, $20 \mu \mathrm{m}$. (K) Quantification of the MMP2 staining score from (J). ${ }^{* *} \mathrm{P}<0.01$ vs. normal tissues. ccRCC, clear cell renal cell carcinoma; G6PD, glucose-6-phosphate dehydrogenase; IHC, immunohistochemistry; KD, knockdown; OE, overexpressing; RT-qPCR, reverse transcription quantitative PCR

the expression of various proteins, including ERK, p38, JNK and their phosphorylated forms, which are involved in the MAPK signaling pathway in G6PD overexpressing or knocked down ccRCC cells. The results demonstrated an increased expression ratio of the phosphorylated ( $\mathrm{p}-$ ) forms of ERK, p38 and JNK in G6PD overexpressing cells. Conversely, expression of p-ERK/ERK, p-p38/p38 and p-JNK/JNK were decreased in G6PD knocked down cells (Fig. 3D-F). These results demonstrated that G6PD overexpression may enhance ROS accumulation and activate MAPK signaling pathway, suggesting that there may be an association between ROS production and MAPK signaling pathway activation in ccRCC cells.

ROS activates the MAPK signaling pathway. To determine whether ROS accumulation could activate MAPK signaling pathway and increase MMP2 expression, NAC and $\mathrm{H}_{2} \mathrm{O}_{2}$ were used to inhibit or increase ROS generation in 786-O cells. Subsequently, the expression of MAPK family members, and the mRNA and protein expression of 
A

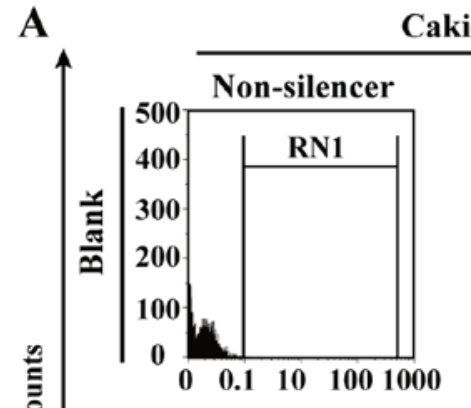

Caki-1

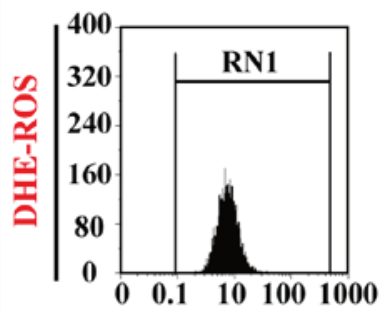

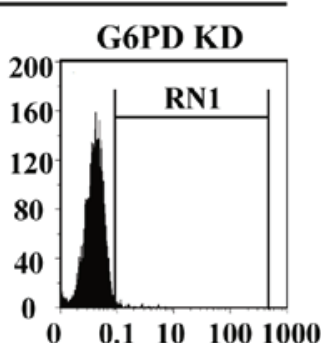

B
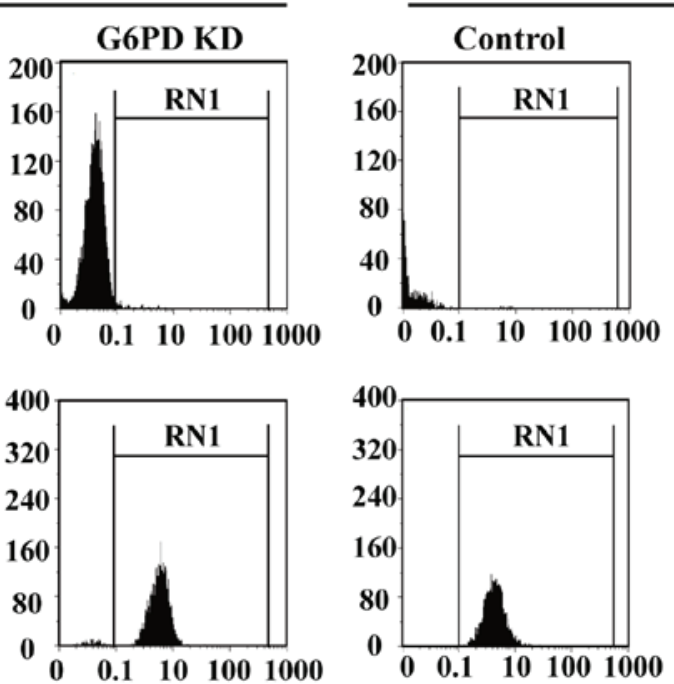

ACHN
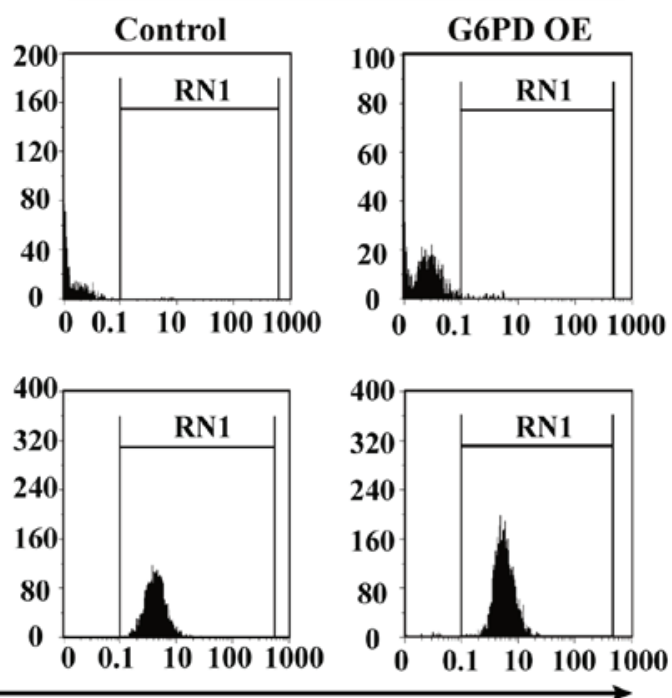

FL3-DHE

C

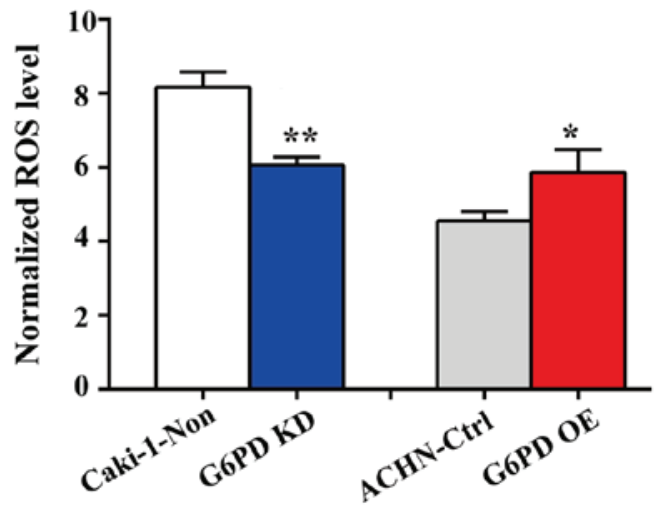

$\mathbf{E}$

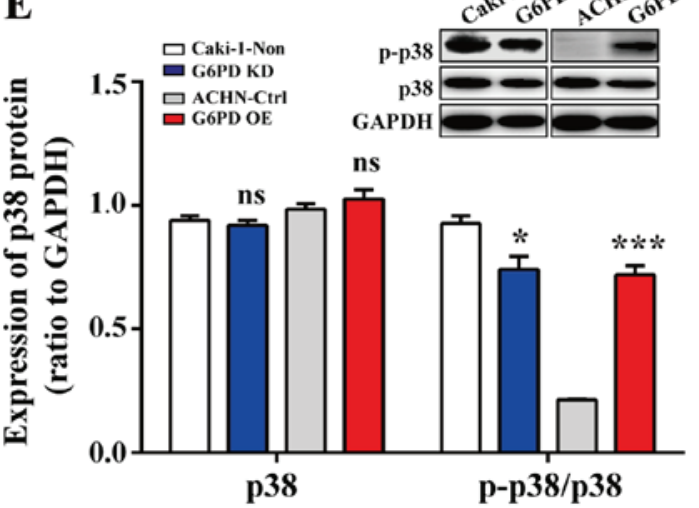

D
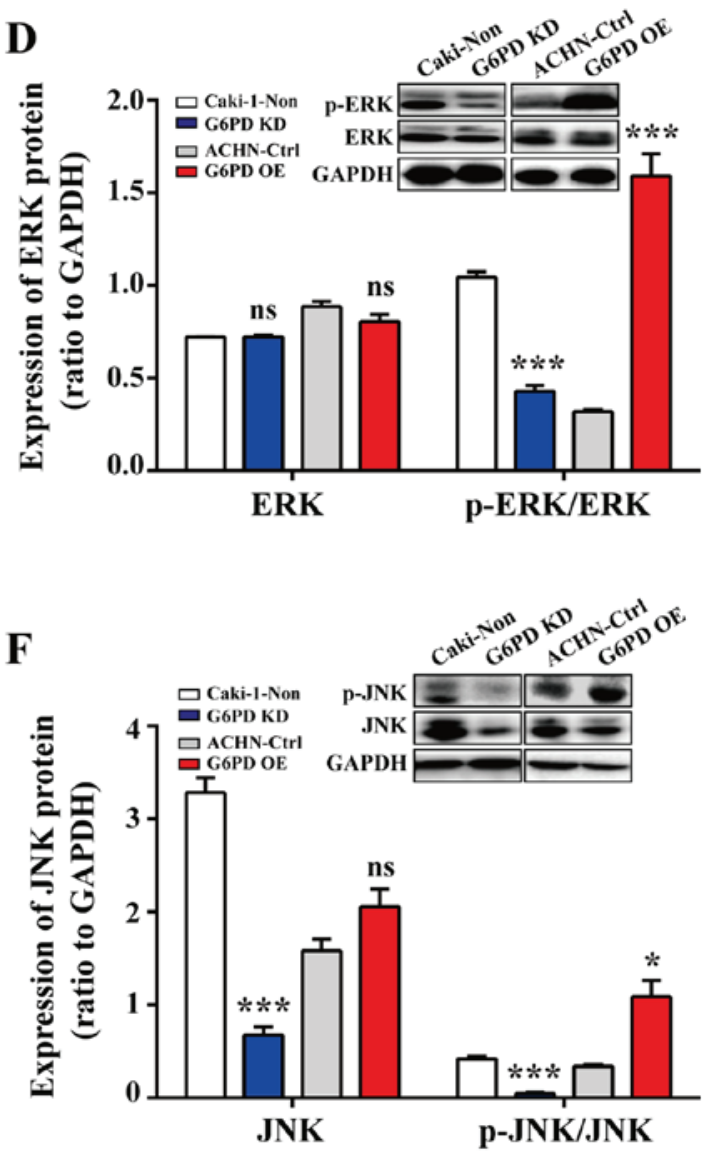

Figure 3. G6PD overexpression enhanced ROS accumulation and activated MAPK signaling pathway in ccRCC cells. (A and B) DHE-ROS analysis by flow cytometry was used for ROS level detection in (A) G6PD-knockdown Caki-1 cells and (B) G6PD-overexpressing ACHN cells. (C) Quantitative analysis of ROS level. Western blotting analysis and quantification of (D) p-ERK, ERK and p-ERK/ERK, (E) p-p38, p38 and p-p38/p38 and (F) p-JNK, JNK and p-JNK/JNK in G6PD-knocked down Caki-1 cells and G6PD-overexpressing ACHN cells. GAPDH was used as an internal control. Each analysis was performed at least three times. Data were expressed as the means \pm standard deviation. ${ }^{*} \mathrm{P}<0.05,{ }^{* *} \mathrm{P}<0.01$ and ${ }^{* * * *} \mathrm{P}<0.001$ vs. non-silencer or control. ns, not significant; Ctrl, control; DHE, dihydroethidium; G6PD, glucose-6-phosphate dehydrogenase; KD, knockdown; ns, not significant; OE, overexpressing; p, phosphorylated; ROS, reactive oxygen species.

MMP2 were evaluated. The results demonstrate that ROS level was decreased in NAC-treated cells and increased in $\mathrm{H}_{2} \mathrm{O}_{2}$-treated cells compared with the control (Fig. 4A and B). Furthermore, the results from western blotting demonstrated that expression ratios of p-ERK/ERK, p-p38/p38 and $\mathrm{p}-\mathrm{JNK} / \mathrm{JNK}$ was decreased in NAC-treated cells, whereas it was increased in $\mathrm{H}_{2} \mathrm{O}_{2}$-treated cells (Fig. 4C-E). These findings suggested that ROS may activate the MAPK signaling 

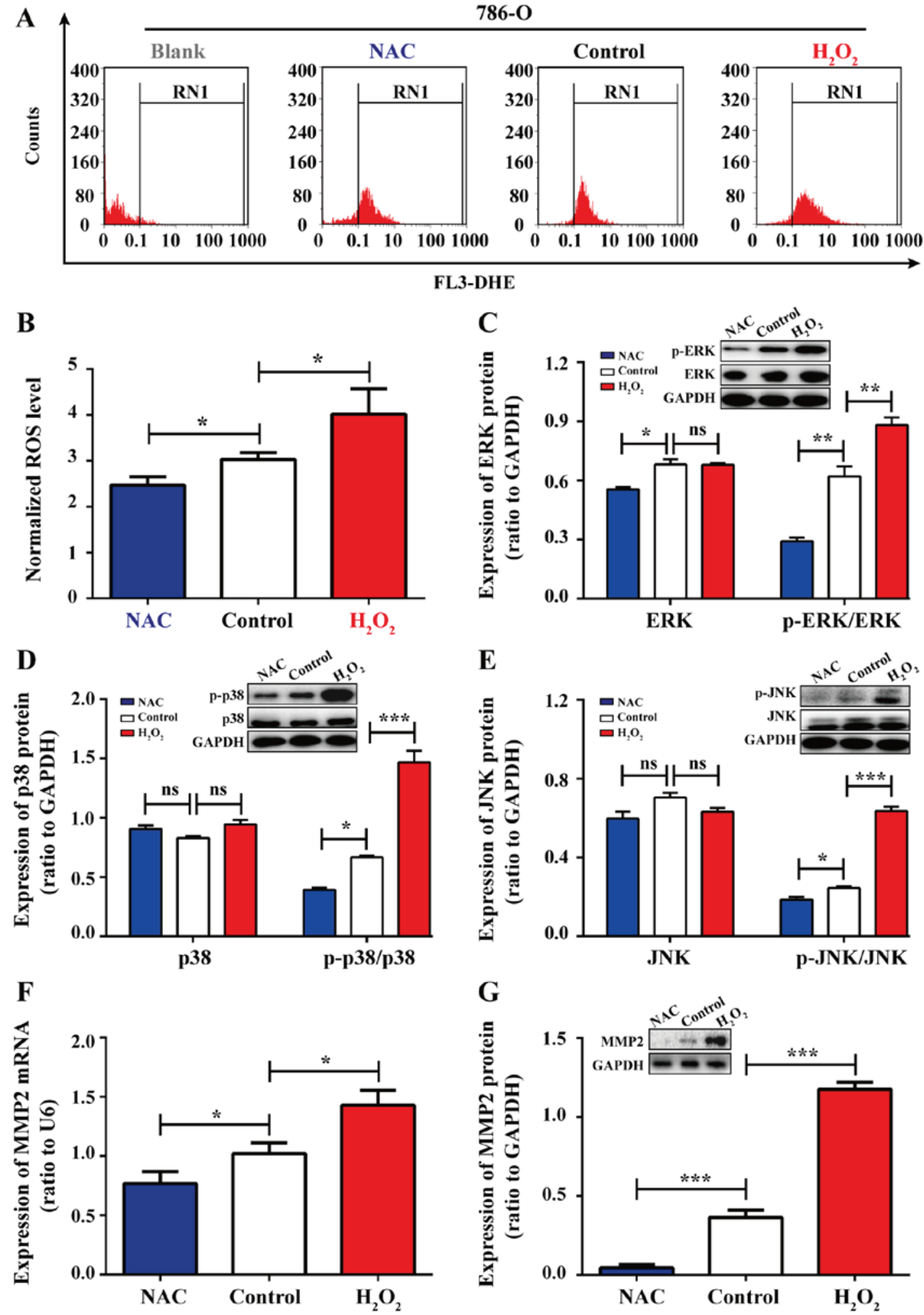

Figure 4. ROS stimulated MAPK signaling pathway activation in clear cell renal cell carcinoma cells. (A) DHE-ROS analysis by flow cytometry and (B) quantitative analysis of ROS level in 786-O cells following treatment with the ROS scavenger NAC (20 mM, $24 \mathrm{~h})$ or ROS generator $\mathrm{H}_{2} \mathrm{O}_{2}(1 \mathrm{mM}, 2 \mathrm{~h})$. (C-E) Western blotting of (C) p-ERK, ERK and p-ERK/ERK, (D) p-p38, p38 and p-p38/p38 and (E) p-JNK, JNK and p-JNK/JNK in 786-O cells following treatment with $\mathrm{NAC}$ or $\mathrm{H}_{2} \mathrm{O}_{2}$. (F) mRNA expression and (G) protein expression of MMP2 in 786-O cells following treatment with NAC or $\mathrm{H}_{2} \mathrm{O}_{2}$. U6 or GAPDH was used as an internal control. Each analysis was performed at least three times and each sample assessed in triplicate. Data were expressed as the means \pm standard deviation. ns, Non-significance; ${ }^{*} \mathrm{P}<0.05,{ }^{* * *} \mathrm{P}<0.01$ and ${ }^{* * * *} \mathrm{P}<0.001$ vs. control. ns, not significant; DHE, dihydroethidium; MMP2, matrix metalloproteinase 2; NAC, N-acetylcysteine; ns, not significant; p, phosphorylated; ROS, reactive oxygen species.

pathway. MMP2 mRNA expression and protein expression were decreased in NAC-treated cells, whereas they were increased in $\mathrm{H}_{2} \mathrm{O}_{2}$-treated cells compared with control (Fig. 4F and G). Taken together, these results suggested that 


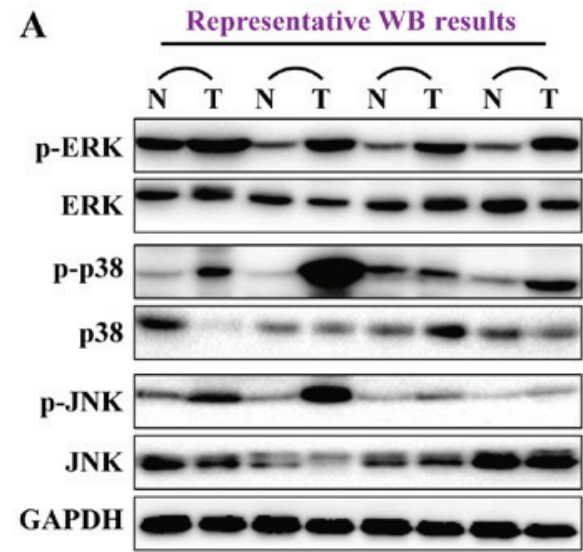

B Protein level

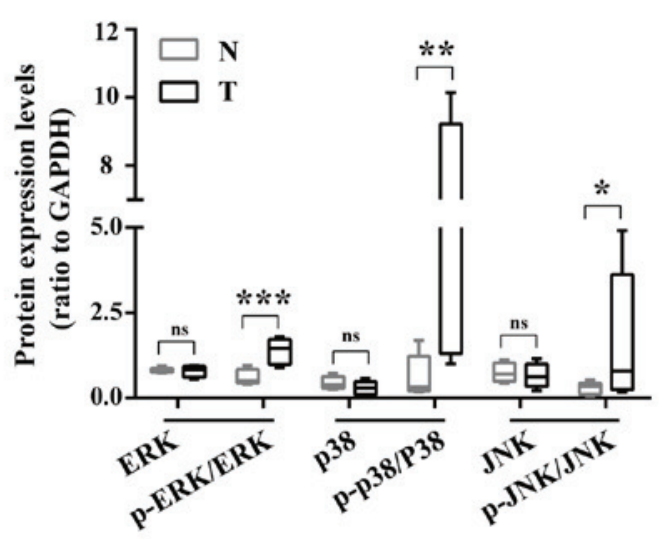

C
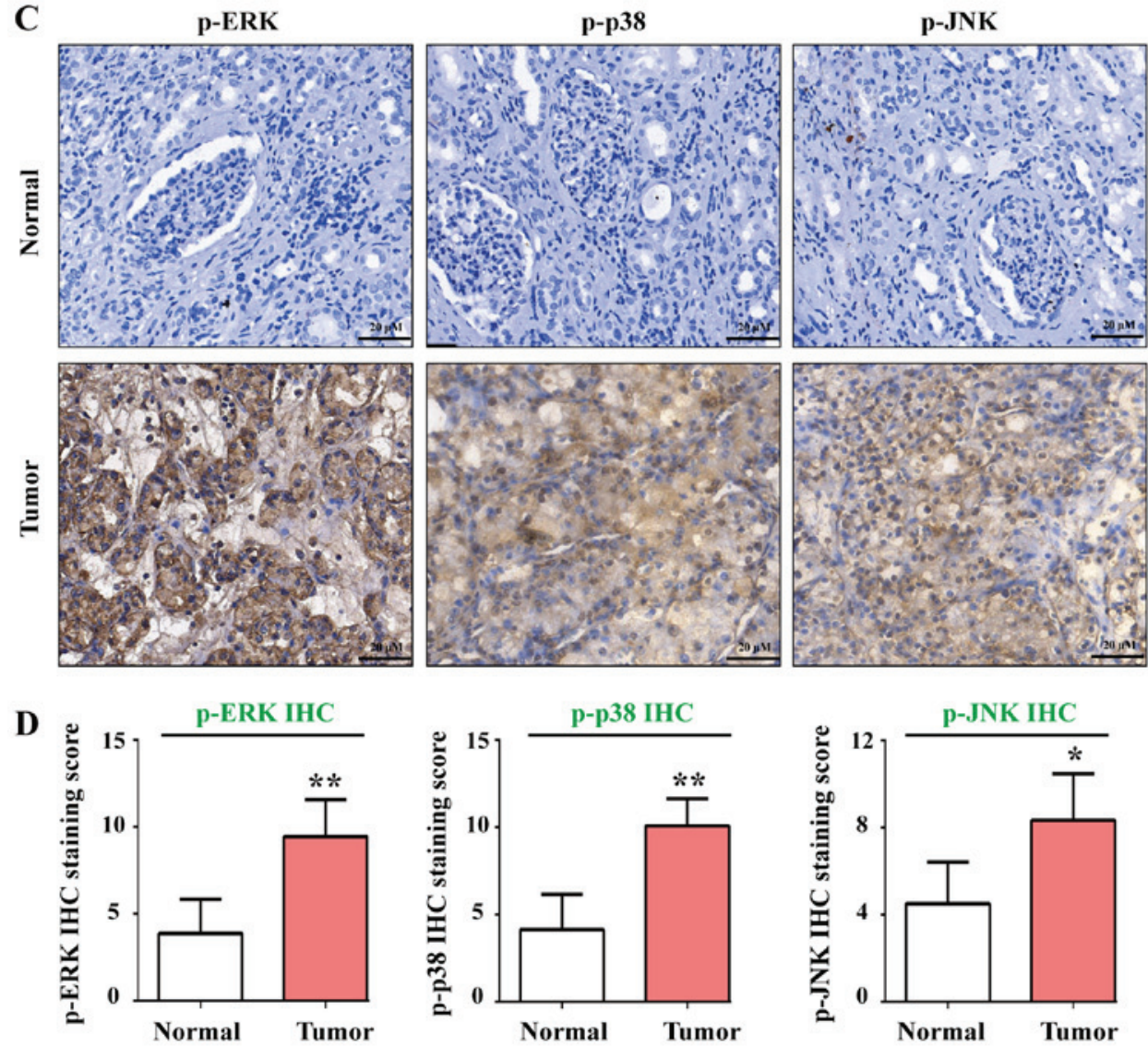

Figure 5. MAPK signaling pathway is overactivated in clear cell renal cell carcinoma. (A and B) Western blotting and (C and D) IHC were used to determine MAPK signaling activation in 20 pairs of ccRCC specimens and matched adjacent normal tissues. (D) Quantification of the staining scores for p-ERK, p-p38 and p-JNK. Data were expressed as the means \pm standard deviation ${ }^{*} \mathrm{P}<0.05,{ }^{* * *} \mathrm{P}<0.01$ and ${ }^{* * * *} \mathrm{P}<0.001$ vs. normal tissues. ns, not significant; IHC, immunohistochemistry; p, phosphorylated.

interactions between G6PD-mediated ROS production and MAPK signaling pathway activation may promote MMP2 expression and contribute to ccRCC invasion.

MAPK signaling pathway is activated in ccRCC tissues. To verify whether the aforementioned results were seen in vivo, MAPK signaling pathway activation was evaluated in ccRCC tissues compared with normal tissues by western blotting and IHC. The results from western blotting demonstrated that expression of total protein expression of ERK, p38 or JNK was not different in tumor samples compared with normal samples; however, p-ERK/ERK, p-p38/p38 and p-JNK/JNK ratios were significantly increased in ccRCC tissues compared with adjacent normal tissues (Fig. 5A and B). Furthermore, the results from IHC demonstrated that p-ERK, p-p38 and p-JNK staining scores were significantly increased in tumor tissues compared with normal tissues (Fig. 5C and D). Taken together, these findings demonstrated that MAPK signaling pathway is over-activated in ccRCC tissues, which may in part contribute to ccRCC invasion following MMP2 overexpression.

MAPK signaling pathway contributes to MMP2 overexpression in ccRCC cells. The aforementioned results suggested that MAPK over-activation may contribute to 
A

Caki-1

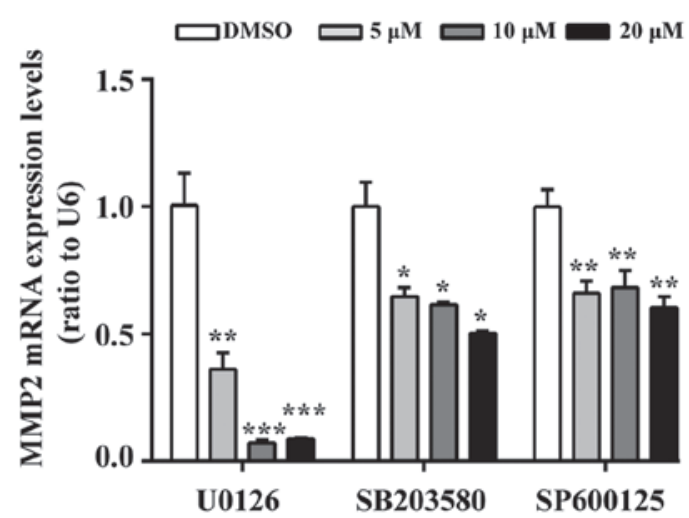

C

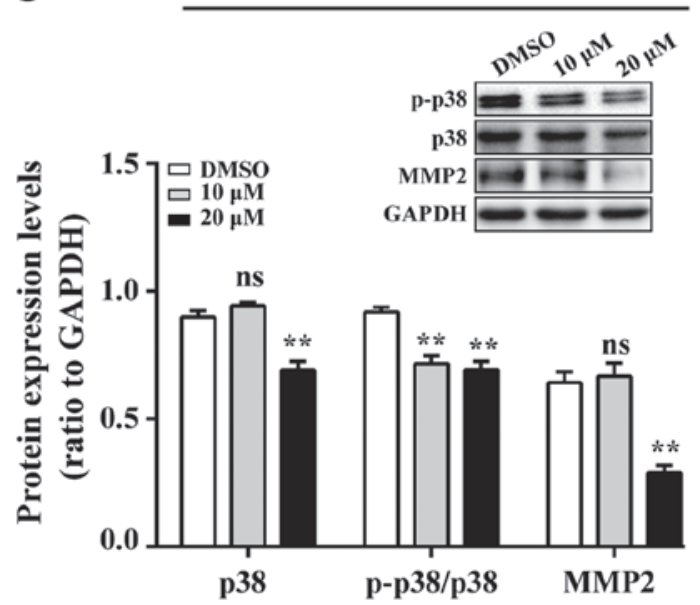

B

ERK inhibitor-U0126

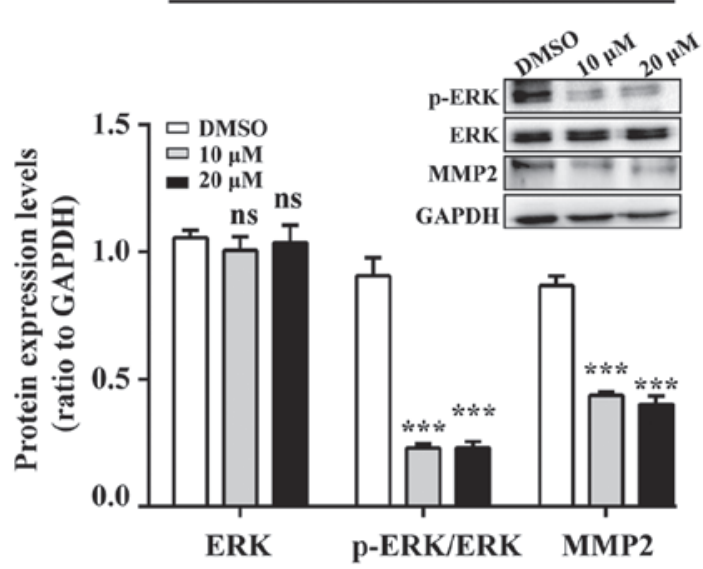

D

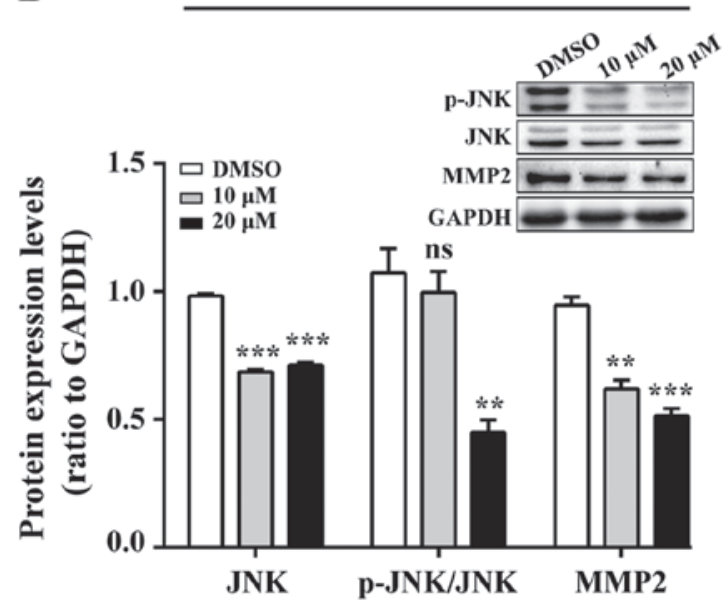

Figure 6. MAPK signaling pathway contributed to MMP2 overexpression in clear cell renal cell carcinoma. (A) MMP2 mRNA expression was determined by reverse transcription quantitative PCR in Caki-1 cells treated with the MAPK signaling inhibitors U0126, SB203580 or SP600125 for 24 h. U6 was used as an internal control. (B-D) Western blotting of (B) P-ERK, ERK, p-ERK/ERK and MMP2, (C) p-p38, p38, p-p38/p38 and MMP2 and (D) p-JNK, JNK, p-JNK/JNK and MMP2 in Caki-1 cells after treatment with U0126, SB203580 or SP600125, respectively. GAPDH was used as an internal control. Each analysis was performed at least three times and each sample assessed in triplicate. Data were expressed as the means \pm standard deviation. ${ }^{*} \mathrm{P}<0.05{ }^{,{ }^{* *} \mathrm{P}<0.01}$ and ${ }^{* * *} \mathrm{P}<0.001$ vs. DMSO. ns, not significant; MMP2, matrix metalloproteinase 2; ns, not significant; p, phosphorylated.

G6PD-mediated ccRCC invasion via MMP2 upregulation. To detect the potential interaction between MAPK signaling pathway and MMP2 expression in ccRCC cells, Caki-1 cells were treated with specific inhibitors of the MAPK pathway, and RT-qPCR was performed to identify MMP2 mRNA expression. The results demonstrated that MMP2 mRNA level was significantly decreased in Caki-1 cells following treatment with ERK inhibitor U0126, p38 inhibitor SB203580 and JNK inhibitor SP600125 (Fig. 6A). In addition, MMP2, p-ERK/ERK, p-p38/p38 and p-JNK/JNK protein expressions were significantly decreased in Caki-1 cells following treatment with the three inhibitors (Fig. 6B-D). Taken together, these data indicated that over-activated MAPK signaling pathway may contribute to MMP2 overexpression in ccRCC cells.

G6PD overexpression upregulates MMP2 in vivo. To further evaluate the role of G6PD in ccRCC growth, in vivo experiments were conducted. Mouse xenograft models were designed by inoculating G6PD-knocked down Caki-1 cells,
G6PD-overexpressing ACHN cells or their control into nude mice. The results demonstrated that G6PD knockdown in Caki-1 cells induced smaller tumors, and the volume of a single tumor in the Non-silencer and G6PD KD group was 634.54 and $552.06 \mathrm{~mm}^{3}$, respectively. However, G6PD overexpressing $\mathrm{ACHN}$ cells produced larger tumors and the volume of a single tumor in the Control and G6PD OE group was 367.27 and $540.81 \mathrm{~mm}^{3}$, respectively (Fig. 7A-B). Furthermore, the mRNA and protein expressions of G6PD and MMP2 in the mice tumors were evaluated by RT-qPCR and western blotting, respectively. The results were consistent with results from in vitro experiments. As presented in Fig. 7C and D, G6PD knockdown significantly downregulated MMP2 expression level, whereas G6PD overexpression significantly increased MMP2 mRNA expression. The results from Figs. 7E and $\mathrm{S} 2$ demonstrated that protein expression of G6PD and MMP2 was significantly decreased in G6PD knockdown Caki-1-derived tumor tissues, whereas G6PD and MMP2 expressions were significantly increased in G6PD overexpressing ACHN-derived tumor specimens 
A
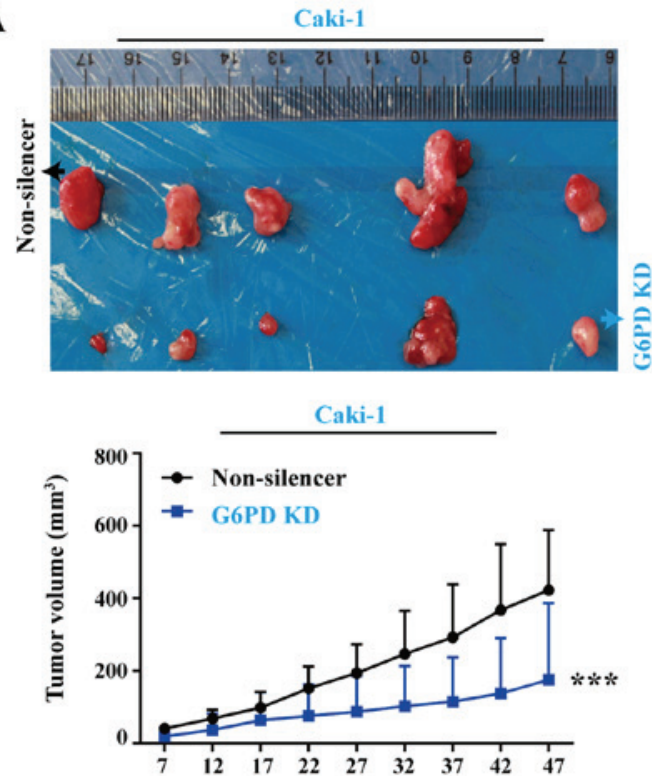

B
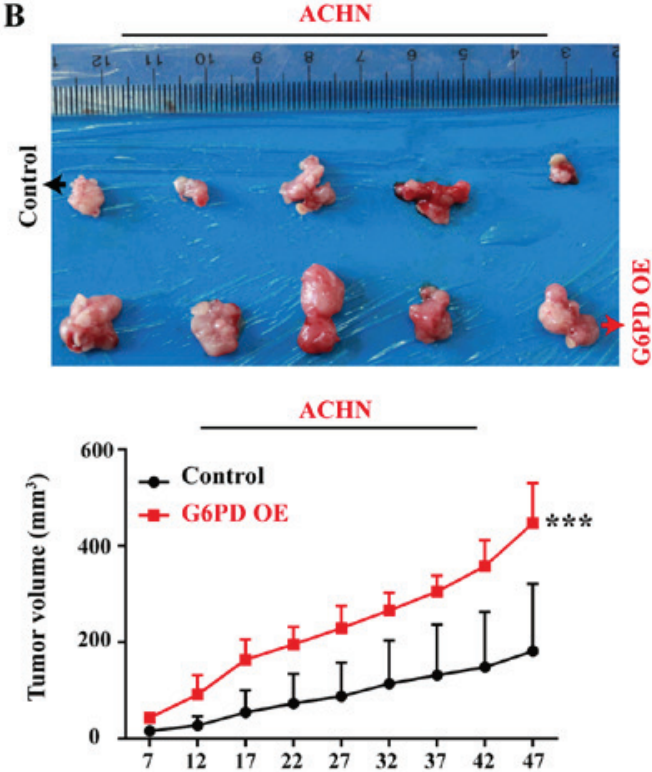

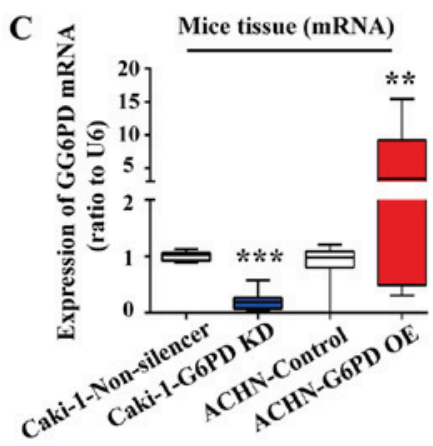

D

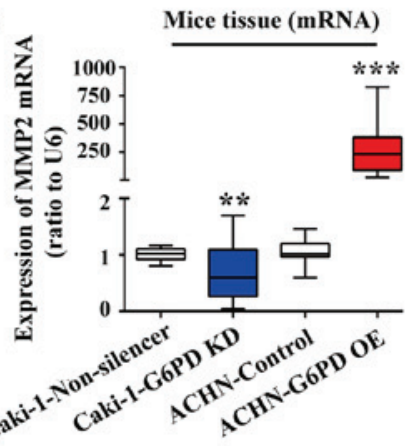

E $\quad$ Mice tissue (protein)
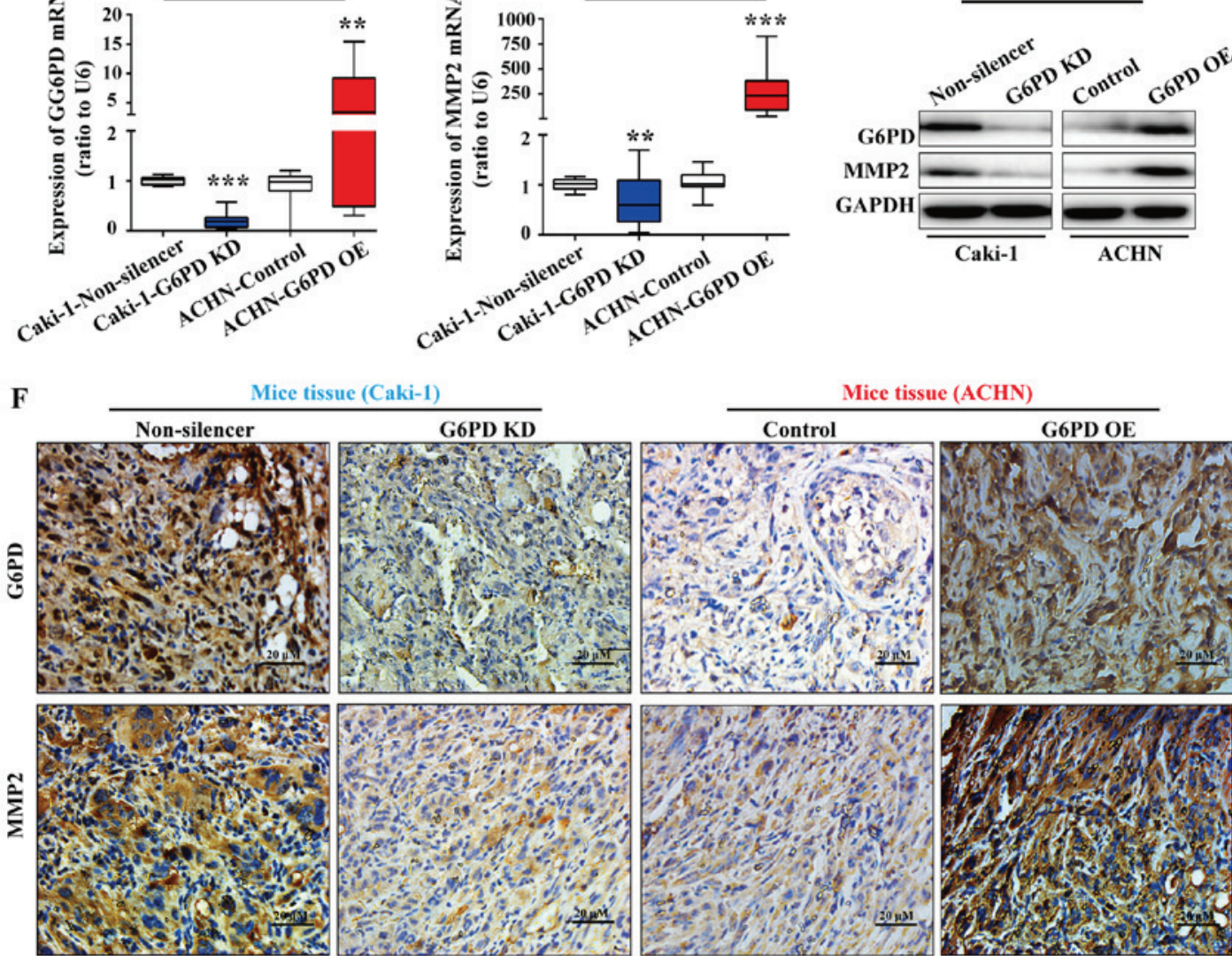

Figure 7. G6PD facilitated MMP2 upregulation in the tumors of mouse xenograft models. (A and B) Stable G6PD knocked down Caki-1 cells, G6PD overexpressing $\mathrm{ACHN}$ cells and corresponding control cells were subcutaneous injected in mice ( $\mathrm{n}=5$ for each group). After 47 days, mice were euthanized, tumors were collected (top panel) and tumor growth curves were analyzed (bottom panel). (C and D) mRNA expression of (C) G6PD and (D) MMP2 in tumors analyzed by Real-time reverse transcription quantitative PCR. (E) G6PD and MMP2 protein expression assessed by western blotting in mice tumors. GAPDH served as a loading control. Each analysis was performed at least three. Data were expressed as the means \pm standard deviation. ${ }^{* *} \mathrm{P}<0.01$ and ${ }^{* * * * *} \mathrm{P}<0.001$ vs. non-silencer or control. (F) Immunohistochemistry analysis of G6PD and MMP2 in mice tumors. Scale bar, $20 \mu \mathrm{m}$. G6PD, glucose-6-phosphate dehydrogenase; KD, knockdown; MMP2, matrix metalloproteinase 2; OE, overexpressing.

compared with the control group. Furthermore, G6PD and MMP2 expressions were evaluated by IHC in tumor xenografts. The results demonstrated that the staining density and intensity of G6PD and MMP2 were weaker in G6PD knockdown Caki-1-derived tumor tissues, whereas they were stronger in G6PD overexpressing ACHN-derived tumor specimens compared with the control group (Fig. 7F). Taken together, these data indicated that G6PD may positively 


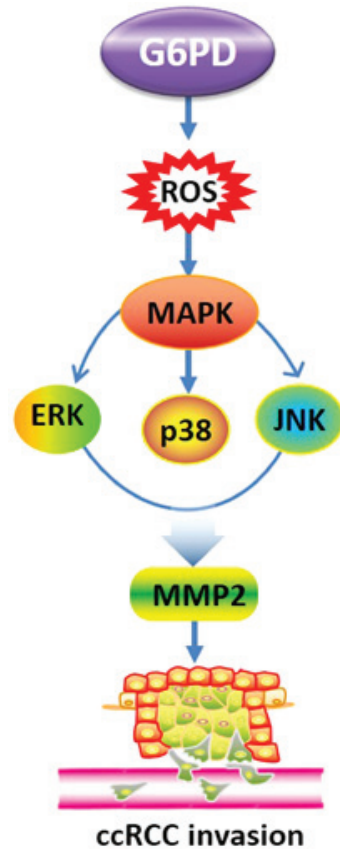

Figure 8. G6PD may promote ccRCC invasion by enhancing MMP2 expression through ROS-MAPK axis pathway. ccRCC, clear cell renal cell carcinoma; G6PD, glucose-6-phosphate dehydrogenase; MMP2, matrix metalloproteinase 2 ; ROS, reactive oxygen species.

regulate MMP2 expression and may therefore contribute to ccRCC growth.

\section{Discussion}

Previous studies reported that G6PD serves a key role in the development of various types of human cancer, including RCC (16,45-49). G6PD, which is the rate-limiting enzyme of the PPP, is overexpressed in numerous cancers and contributes to tumor growth. In a previous study conducted in our laboratory, we found that G6PD overexpression promoted RCC cell proliferation and tumorigenesis through the positive feedback regulation of p-STAT3 (16). A recent study demonstrated that the blockade of G6PD by polydatin not only leads to cell cycle arrest and cell apoptosis, but also inhibits tumor cell invasion, reduces tumor size and inhibits lymph node metastasis, indicating therefore the crucial role of G6PD in tumor progression (50). Furthermore, the G6PD/hypoxia-inducing factor $1 \alpha$ pathway has been implicated in the nuclear factor-erythroid 2-related factor 2-mediated breast cancer migration (48). Lu et al (51) reported that elevated G6PD expression is associated with the poor prognosis of patients with hepatocellular carcinoma, and that G6PD overexpression contributes to migration and invasion of hepatocellular carcinoma cells by stimulating the epithelial-mesenchymal transition. Despite these accumulating evidence on the role of G6PD in cancer progression, whether G6PD could mediate RCC invasion, and by which underlying mechanisms, remain unclear. The present study aimed therefore to clarify the role of G6PD in ccRCC invasion.

It has been reported that MMP2 is overexpressed in tissues from patients with RCC and involved in RCC invasion (32-34). Furthermore, a case-control study and meta-analysis demonstrated that increased MMP2 protein expression is positively correlated with tumor metastasis $(52,53)$. The MAPK signaling pathway is largely implicated in the progression and metastasis of various types of cancer, including RCC (54,55). The p38/MAPK, ERK/MAPK and JNK/MAPK cascades are commonly involved in the malignant progression of RCC $(56,57)$. In addition, previous studies reported an association between increased expression of MMPs and activation of the MAPK signaling pathway $(37,58)$, and between ROS overproduction and activation of the MAPK signaling pathway $(22,24)$. The results from the present study and from previous studies suggested that G6PD may promote ROS production in RCC cells $(16,49)$. Previous studies also reported a possible interaction between G6PD expression and the MAPK signaling pathway $(59,60)$.

The present study hypothesized that G6PD could be involved in ccRCC invasion through the ROS-MAPK-MMPs axis. To do so, stable ccRCC cells lines where G6PD was overexpressed or knocked down were designed. Subsequently, the effect of G6PD expression on ccRCC cell invasive ability was assessed. The results demonstrated that G6PD overexpression increased ccRCC cell invasive ability, whereas its downregulation had the opposite effect. These findings suggested that G6PD may facilitate ccRCC invasion (16). To determine the underlying mechanisms of G6PD, MMP2 expression level was evaluated, and the results demonstrated that MMP2 was overexpressed in G6PD overexpressing cells. Subsequently, MMP2 and G6PD expression levels were evaluated in ccRCC tumor tissues and adjacent normal tissues, and their correlation was determined. The results demonstrated that both MMP2 and G6PD expression were increased in tumor tissues compared to normal tissues. In addition, results from Pearson correlation analysis demonstrated a positive correlation between MMP2 and G6PD expression, suggesting that MMP2 overexpression may be dependent of G6PD dysregulation in ccRCC. Moreover, upregulated MMP2 expression following G6PD overexpression was observed in xenografted mice model. Taken together, these findings indicated that G6PD may stimulate ccRCC invasion by upregulating MMP2.

Activation of the MAPK signaling pathway was then evaluated in ccRCC. In this study, the MAPK signaling pathway included ERK, p38 and JNK kinases. Once these proteins are phosphorylated, they interact with their substrates, leading to stimulation of certain biological processes, including cell proliferation and migration $(61,62)$. The results from the present study revealed that the expression of p-ERK, p-p38 and p-JNK was significantly increased in ccRCC tissues compared with normal tissues, suggesting that the MAPK signaling pathway was activated in ccRCC. Furthermore, the expression ratios of p-ERK/ERK, p-p38/p38 and p-JNK/JNK was increased in G6PD overexpressing cells and decreased in G6PD knocked down cells, indicating that activation of the MAPK signaling pathway may depend on G6PD regulation. In addition, the present study confirmed that G6PD overexpression could enhance ROS production in ccRCC cells. Furthermore, MAPK signaling pathway activation was found to be positively regulated following ROS accumulation. These results were obtained by assessing the expression of p-ERK, p-p38 and p-JNK in cells treated with the ROS scavenger NAC and the ROS generator $\mathrm{H}_{2} \mathrm{O}_{2}$. The results demonstrated that the 
expression ratios of p-ERK/ERK, p-p38/p38 and p-JNK/JNK was decreased and increased in ccRCC cells treated with NAC or $\mathrm{H}_{2} \mathrm{O}_{2}$, respectively. Eventually, the potential relation between ROS accumulation and MMP2 expression, and between MAPK signaling pathway activation and MMP2 expression was evaluated. The results demonstrated that MMP2 mRNA and protein expression levels were decreased and increased following NAC or $\mathrm{H}_{2} \mathrm{O}_{2}$ stimulation, respectively. In addition, the expression ratios of p-ERK/ERK, p-p38/p38, p-JNK/JNK and MMP2 was decreased following cell treatment with relevant MAPK signaling pathway inhibitors. ROS-mediated MAPK signaling pathway dysregulation may therefore contribute to MMP2 overexpression in ccRCC cells.

In summary, the present study demonstrated that G6PD may facilitate ccRCC invasion, probably by enhancing MMP2 expression through the ROS-MAPK axis pathway (Fig. 8). The results from the present study confirmed the oncogenic role of G6PD in ccRCC progression, and may contribute to the better understanding of ccRCC invasion and the development of novel therapeutic options for ccRCC.

\section{Acknowledgments}

Not applicable.

\section{Funding}

This study was supported by the National Natural Science Foundation ofChina(grant.nos.81960462,31960145,81760455, 31960200, 81560037, 81460421, 31660246 and 81660135) and the Yunnan Province Applied Basic Research Funds [grant. nos. 2018FE468(-001), 2017FE468(-132), 2017FE468(-003), 2017FE468(-141), 2017FE468(-072) and 2018FB120].

\section{Availability of data and materials}

All data generated or analyzed during this study are included in this published article.

\section{Authors' contributions}

YZ and YK were responsible for the experiments design and results interpretation. YN performed the MMPs and MAPK inhibitors related experiments. YK, XY and ZeY collected the human clear cell renal cell carcinoma specimens. YN, XY and $\mathrm{ZiY}$ were in charge of the immunohistochemistry analysis. $\mathrm{QH}$ and $\mathrm{HB}$ performed the other experiments. QZ verified all results, organized figures and wrote the manuscript with the help of YLA, ZeY and YZ. All authors read and approved the final manuscript.

\section{Ethics approval and consent to participate}

Experiments involving human samples were performed in accordance with the regulations of Helsinki Declaration and approved by the Ethics Committee of Kunming Medical University. All patients provided written informed consent. All animal experiments were performed according to the Regulations for the Administration of Affairs Concerning Experimental Animals (China, 1988) and approved by the
Institutional Animal Care and Use Committee of Kunming Medical University.

\section{Patient consent for publication}

Not applicable.

\section{Competing interests}

The authors declare they have no competing interests.

\section{References}

1. Global Burden of Disease Cancer Collaboration, Fitzmaurice C, Akinyemiju TF, Al Lami FH, Alam T, Alizadeh-Navaei R, Allen C, Alsharif U, Alvis-Guzman N, Amini E, et al: Global, regional, and national cancer incidence, mortality, years of life lost, years lived with disability, and disability-adjusted life-years for 29 cancer groups, 1990 to 2016: A systematic analysis for the global burden of disease study. JAMA Oncol 4: 1553-1568, 2018.

2. Global Burden of Disease Cancer Collaboration, Fitzmaurice C, Abate D, Abbasi N, Abbastabar H, Abd-Allah F, Abdel-Rahman O, Abdelalim A, Abdoli A, Abdollahpour I, et al: Global, regional, and national cancer incidence, mortality, years of life lost, years lived with disability, and disability-adjusted life-years for 29 cancer groups, 1990 to 2017: A systematic analysis for the global burden of disease study. JAMA Oncol 5: 1749-1768, 2019.

3. Siegel RL, Miller KD and Jemal A: Cancer statistics, 2020. CA Cancer J Clin 70: 7-30, 2020.

4. Gupta K, Miller JD, Li JZ, Russell MW and Charbonneau C: Epidemiologic and socioeconomic burden of metastatic renal cell carcinoma (mRCC): A literature review. Cancer Treat Rev 34: 193-205, 2008.

5. Chang Y,Li N, Yuan W, Wang G and Wen J: LINC00997, a novel long noncoding RNA, contributes to metastasis via regulation of S100A11 in kidney renal clear cell carcinoma. Int J Biochem Cell Biol 116: 105590, 2019.

6. Ferronika P, Hof J, Kats-Ugurlu G, Sijmons RH, Terpstra MM, de Lange K, Leliveld-Kors A, Westers $H$ and Kok K: Comprehensive profiling of primary and metastatic ccRCC reveals a high homology of the metastases to a subregion of the primary tumour. Cancers (Basel) 11: E812, 2019.

7. Hanahan D and Weinberg RA: Hallmarks of cancer: The next generation. Cell 144: 646-674, 2011.

8. Poulain L, Sujobert P, Zylbersztejn F, Barreau S, Stuani L, Lambert M, Palama TL, Chesnais V, Birsen R, Vergez F, et al: High mTORC1 activity drives glycolysis addiction and sensitivity to G6PD inhibition in acute myeloid leukemia cells. Leukemia 31: 2326-2335, 2017.

9. Wen SS, Zhang TT, Xue DX, Wu WL, Wang YL, Wang Y, Ji QH, Zhu YX, Qu N and Shi RL: Metabolic reprogramming and its clinical application in thyroid cancer. Oncol Lett 18: 1579-1584, 2019.

10. Jiao Y, Li Y, Jiang P, Han W and Liu Y: PGM5: A novel diagnostic and prognostic biomarker for liver cancer. PeerJ 7: e7070, 2019.

11. Duan JJ, Cai J, Guo YF, Bian XW and Yu SC: ALDH1A3, a metabolic target for cancer diagnosis and therapy. Int J Cancer 139: 965-975, 2016.

12. Yang HC, Wu YH, Yen WC, Liu HY, Hwang TL, Stern A and Chiu DT: The Redox role of G6PD in cell growth, cell death, and cancer. Cells 8: E1055, 2019.

13. Pu H, Zhang Q, Zhao C, Shi L, Wang Y, Wang J and Zhang M: Overexpression of G6PD is associated with high risks of recurrent metastasis and poor progression-free survival in primary breast carcinoma. World J Surg Oncol 13: 323, 2015.

14. Zhang Q, Yi X, Yang Z, Han Q, Di X, Chen F, Wang Y, Yi Z, Kuang Y and Zhu Y: Overexpression of G6PD represents a potential prognostic factor in clear cell renal cell carcinoma. J Cancer 8: 665-673, 2017.

15. Nagashio R, Oikawa S, Yanagita K, Hagiuda D, Kuchitsu Y, Igawa S, Naoki K, Satoh Y, Ichinoe M, Murakumo Y, et al: Prognostic significance of G6PD expression and localization in lung adenocarcinoma. Biochim Biophys Acta Proteins Proteom 1867: 38-46, 2019 
16. Zhang Q, Yang Z, Han Q, Bai H, Wang Y, Yi X, Yi Z, Yang L, Jiang L, Song X, et al: G6PD promotes renal cell carcinoma proliferation through positive feedback regulation of p-STAT3. Oncotarget 8: 109043-109060, 2017.

17. Rhee SG: Cell signaling. $\mathrm{H} 2 \mathrm{O} 2$, a necessary evil for cell signaling. Science 312: 1882-1883, 2006.

18. Pelicano H, Carney D and Huang P: ROS stress in cancer cells and therapeutic implications. Drug Resist Updat 7: 97-110, 2004

19. Fan TF, Wu TF, Bu LL, Ma SR, Li YC, Mao L, Sun ZJ and Zhang WF: Dihydromyricetin promotes autophagy and apoptosis through ROS-STAT3 signaling in head and neck squamous cell carcinoma. Oncotarget 7: 59691-59703, 2016.

20. Morgan MJ and Liu ZG: Crosstalk of reactive oxygen species and NF- $\kappa$ B signaling. Cell Res 21: 103-115, 2011.

21. Li G, Liao Y, Hu J, Lu L, Zhang Y, Li B and An T: Activation of NF- $\kappa \mathrm{B}$ pathways mediating the inflammation and pulmonary diseases associated with atmospheric methylamine exposure. Environ Pollut 252(Pt B): 1216-1224, 2019.

22. Zhao W, Lu M and Zhang Q: Chloride intracellular channel 1 regulates migration and invasion in gastric cancer by triggering the ROS-mediated p38 MAPK signaling pathway. Mol Med Rep 12: 8041-8047, 2015.

23. Wang C, Li P, Xuan J, Zhu C, Liu J, Shan L, Du Q, Ren Y and Ye J: Cholesterol enhances colorectal cancer progression via ROS elevation and MAPK signaling pathway activation. Cell Physiol Biochem 42: 729-742, 2017.

24. Zhong WF, Wang XH, Pan B, Li F, Kuang L and Su ZX: Eupatilin induces human renal cancer cell apoptosis via ROS-mediated MAPK and PI3K/AKT signaling pathways. Oncol Lett 12 : 2894-2899, 2016.

25. Kim EK, Jang M, Song MJ, Kim D, Kim Y and Jang HH: Redox-mediated mechanism of chemoresistance in cancer cells Antioxidants (Basel) 8: E471, 2019.

26. Xian D, Lai R, Song J, Xiong X and Zhong J: Emerging perspective: Role of increased ROS and redox imbalance in skin carcinogenesis. Oxid Med Cell Longev 2019: 8127362, 2019.

27. Cai T, Kuang Y, Zhang C, Zhang Z, Chen L, Li B, Li Y, Wang Y, Yang H, Han Q and Zhu Y: Glucose-6-phosphate dehydrogenase and NADPH oxidase 4 control STAT3 activity in melanoma cells through a pathway involving reactive oxygen species, c-SRC and SHP2. Am J Cancer Res 5: 1610-1620, 2015.

28. Steeg PS: Tumor metastasis: Mechanistic insights and clinical challenges. Nat Med 12: 895-904, 2006.

29. Schwager SC, Taufalele PV and Reinhart-King CA: Cell-cell mechanical communication in cancer. Cell Mol Bioeng 12: 1-14, 2019.

30. Gonzalez-Avila G, Sommer B, Mendoza-Posada DA, Ramos C, Garcia-Hernandez AA and Falfan-Valencia R: Matrix metalloproteinases participation in the metastatic process and their diagnostic and therapeutic applications in cancer. Crit Rev Oncol Hematol 137: 57-83, 2019.

31. Ricci S, Pinto F, Auletta A, Giordano A, Giovane A, Settembre G, Boccellino M, Boffo S, Di Carlo A and Di Domenico M: The enigmatic role of matrix metalloproteinases in epithelial-to-mesenchymal transition of oral squamous cell carcinoma: Implications and nutraceutical aspects. J Cell Biochem 2019 (Epub ahead of print)

32. Feng X, Yan N, Sun W, Zheng S, Jiang S, Wang J, Guo C, Hao L, Tian Y, Liu S and Sun MZ: miR-4521-FAM129A axial regulation on ccRCC progression through TIMP-1/MMP2/MMP9 and MDM2/p53/Bcl2/Bax pathways. Cell Death Discov 5: 89, 2019.

33. Ogasawara N, Kudo T, Sato M, Kawasaki Y, Yonezawa S, Takahashi S, Miyagi Y, Natori Y and Sugiyama A: Reduction of membrane protein CRIM1 decreases E-cadherin and increases claudin-1 and MMPs, enhancing the migration and invasion of renal carcinoma cells. Biol Pharm Bull 41: 604-611, 2018.

34. Yang SD, Sun RC, Mu HJ, Xu ZQ and Zhou ZY: The expression and clinical significance of TGF-beta1 and MMP2 in human renal clear cell carcinoma. Int J Surg Pathol 18: 85-93, 2010.

35. Chen F, Deng J, Liu X, Li W and Zheng J: HCRP-1 regulates cell migration and invasion via EGFR-ERK mediated up-regulation of MMP-2 with prognostic significance in human renal cell carcinoma. Sci Rep 5: 13470, 2015.

36. Chen CM, Hsieh SC, Lin CL, Lin YS, Tsai JP and Hsieh YH Alpha-mangostin suppresses the metastasis of human renal carcinoma cells by targeting MEK/ERK expression and MMP-9 transcription activity. Cell Physiol Biochem 44: 1460-1470, 2017.
37. Qin H, Liu X, Li F, Miao L, Li T, Xu B, An X, Muth A, Thompson PR, Coonrod SA and Zhang X: PAD1 promotes epithelial-mesenchymal transition and metastasis in triple-negative breast cancer cells by regulating MEK1-ERK1/2-MMP2 signaling. Cancer Lett 409: 30-41, 2017

38. Chauhan A, Ojha R, Semwal DK, Mishra SP and Semwal RB: Combined treatment with CCI779 and SB203580 induces cellular senescence in renal cell carcinoma cell line via p53 pathway. Anticancer Agents Med Chem 17: 1545-1554, 2017.

39. Wu SY, Sung PJ, Chang YL, Pan SL and Teng CM: Heteronemin, a spongean sesterterpene, induces cell apoptosis and autophagy in human renal carcinoma cells. Biomed Res Int 2015: 738241, 2015.

40. Zhang Q, Yang Z, Jia Z, Liu C, Guo C, Lu H, Chen P, Ma K, Wang W and Zhou C: ISL-1 is overexpressed in non-Hodgkin lymphoma and promotes lymphoma cell proliferation by forming a p-STAT3/p-c-Jun/ISL-1 complex. Mol Cancer 13: 181, 2014.

41. Liu Y, Li Y, Li T, Lu H, Jia Z, Wang W, Chen P, Ma K and Zhou C: POU homeodomain protein OCT1 modulates islet 1 expression during cardiac differentiation of P19CL6 cells. Cell Mol Life Sci 68: 1969-1982, 2011.

42. Livak KJ and Schmittgen TD: Analysis of relative gene expression data using real-time quantitative PCR and the 2(-Delta Delta C(T)) method. Methods 25: 402-408, 2001

43. Galperin E, Verkhusha VV and Sorkin A: Three-chromophore FRET microscopy to analyze multiprotein interactions in living cells. Nat Methods 1: 209-217, 2004.

44. You X, Nguyen AW, Jabaiah A, Sheff MA, Thorn KS and Daugherty PS: Intracellular protein interaction mapping with FRET hybrids. Proc Natl Acad Sci USA 103: 18458-18463, 2006

45. Kong DH, Li S, Du ZX, Liu C, Liu BQ, Li C, Zong ZH and Wang HQ: BAG3 elevation inhibits cell proliferation via direct interaction with G6PD in hepatocellular carcinomas. Oncotarget 7: 700-711, 2016.

46. Hu T, Zhang C, Tang Q, Su Y, Li B, Chen L, Zhang Z, Cai T and Zhu Y: Variant G6PD levels promote tumor cell proliferation or apoptosis via the STAT3/5 pathway in the human melanoma xenograft mouse model. BMC Cancer 13: 251, 2013.

47. Xu SN, Wang TS, Li X and Wang YP: SIRT2 activates G6PD to enhance NADPH production and promote leukaemia cell proliferation. Sci Rep 6: 32734, 2016.

48. Zhang HS, Zhang ZG, Du GY, Sun HL, Liu HY, Zhou Z, Gou XM, Wu XH, Yu XY and Huang YH: Nrf2 promotes breast cancer cell migration via up-regulation of G6PD/HIF-1 $\alpha /$ Notch1 axis. J Cell Mol Med 23: 3451-3463, 2019.

49. Lucarelli G, Galleggiante V, Rutigliano M, Sanguedolce F, Cagiano S, Bufo P, Lastilla G, Maiorano E, Ribatti D, Giglio A, et al: Metabolomic profile of glycolysis and the pentose phosphate pathway identifies the central role of glucose-6-phosphate dehydrogenase in clear cell-renal cell carcinoma. Oncotarget 6: 13371-13386, 2015.

50. Mele L, Paino F, Papaccio F, Regad T, Boocock D, Stiuso P, Lombardi A, Liccardo D, Aquino G, Barbieri A, et al: A new inhibitor of glucose-6-phosphate dehydrogenase blocks pentose phosphate pathway and suppresses malignant proliferation and metastasis in vivo. Cell Death Dis 9: 572, 2018.

51. Lu M, Lu L, Dong Q, Yu G, Chen J, Qin L, Wang L, Zhu W and Jia H: Elevated G6PD expression contributes to migration and invasion of hepatocellular carcinoma cells by inducing epithelial-mesenchymal transition. Acta Biochim Biophys Sin (Shanghai) 50: 370-380, 2018.

52. Cheng HP, Duan YR, Li Y, Li XD, Zhu CY and Chen BP: Clinicopathological significance of matrix metalloproteinase-2 protein expression in renal cell carcinoma patients. Anal Quant Cytopathol Histpathol 37: 353-363, 2015.

53. Liu Q, Zhang GW, Zhu CY, Wei JX, Tian X, Li Y and Li XD: Clinicopathological significance of matrix metalloproteinase 2 protein expression in patients with renal cell carcinoma: A case-control study and meta-analysis. Cancer Biomark 16: 281-289, 2016.

54. Zhang G, Yu Z, Fu S, Lv C, Dong Q, Fu C, Kong C and Zeng Y: ERCC6L that is up-regulated in high grade of renal cell carcinoma enhances cell viability in vitro and promotes tumor growth in vivo potentially through modulating MAPK signalling pathway. Cancer Gene Ther 26: 323-333, 2019.

55. Wang DP, Tang XZ, Liang QK, Zeng XJ, Yang JB and Xu J: Overexpression of long noncoding RNA SLC26A4-AS1 inhibits the epithelial-mesenchymal transition via the MAPK pathway in papillary thyroid carcinoma. J Cell Physiol 235: 2403-2413, 2020 . 
56. Li JK, Chen C, Liu JY, Shi JZ, Liu SP, Liu B, Wu DS, Fang ZY, Bao Y, Jiang MM, et al: Long noncoding RNA MRCCAT1 promotes metastasis of clear cell renal cell carcinoma via inhibiting NPR3 and activating p38-MAPK signaling. Mol Cancer 16: $111,2017$.

57. Gao Y, Li J, Qiao N, Meng Q, Zhang M, Wang X, Jia J, Yang S, Qu C, Li W and Wang D: Adrenomedullin blockade suppresses sunitinib-resistant renal cell carcinoma growth by targeting the ERK/MAPK pathway. Oncotarget 7: 63374-63387, 2016.

58. Guan H, Guo Z, Liang W, Li H, Wei G, Xu L, Xiao H and Li Y: Trop2 enhances invasion of thyroid cancer by inducing MMP2 through ERK and JNK pathways. BMC Cancer 17: 486, 2017.

59. Talukdar I, Szeszel-Fedorowicz W and Salati LM: Arachidonic acid inhibits the insulin induction of glucose-6-phosphate dehydrogenase via p38 MAP kinase. J Biol Chem 280: 40660-40667, 2005.
60. Lin HR, Wu YH, Yen WC, Yang CM and Chiu DT: Diminished COX-2/PGE2-mediated antiviral response due to impaired NOX/MAPK signaling in G6PD-knockdown lung epithelial cells. PLoS One 11: e0153462, 2016.

61. Sun Y, Liu WZ, Liu T, Feng X, Yang N and Zhou HF: Signaling pathway of MAPK/ERK in cell proliferation, differentiation, migration, senescence and apoptosis. J Recept Signal Transduct Res 35: 600-604, 2015.

62. Cargnello M and Roux PP: Activation and function of the MAPKs and their substrates, the MAPK-activated protein kinases. Microbiol Mol Biol Rev 75: 50-83, 2011.

(i) This work is licensed under a Creative Commons Attribution-NonCommercial-NoDerivatives 4.0 International (CC BY-NC-ND 4.0) License. 